This item was submitted to Loughborough's Research Repository by the author.

Items in Figshare are protected by copyright, with all rights reserved, unless otherwise indicated.

\title{
Optimizing microneedle arrays for transdermal drug delivery: extension to non-square distribution of microneedles
}

PLEASE CITE THE PUBLISHED VERSION

\section{PUBLISHER}

(C) Informa Healthcare (Taylor and Francis Group)

\section{VERSION}

AM (Accepted Manuscript)

\section{LICENCE}

CC BY-NC-ND 4.0

\section{REPOSITORY RECORD}

Al-Qallaf, Barrak, and Diganta Bhusan Das. 2009. "Optimizing Microneedle Arrays for Transdermal Drug Delivery: Extension to Non-square Distribution of Microneedles”. figshare. https://hdl.handle.net/2134/4341. 
This item was submitted to Loughborough's Institutional Repository (https://dspace.lboro.ac.uk/) by the author and is made available under the following Creative Commons Licence conditions.

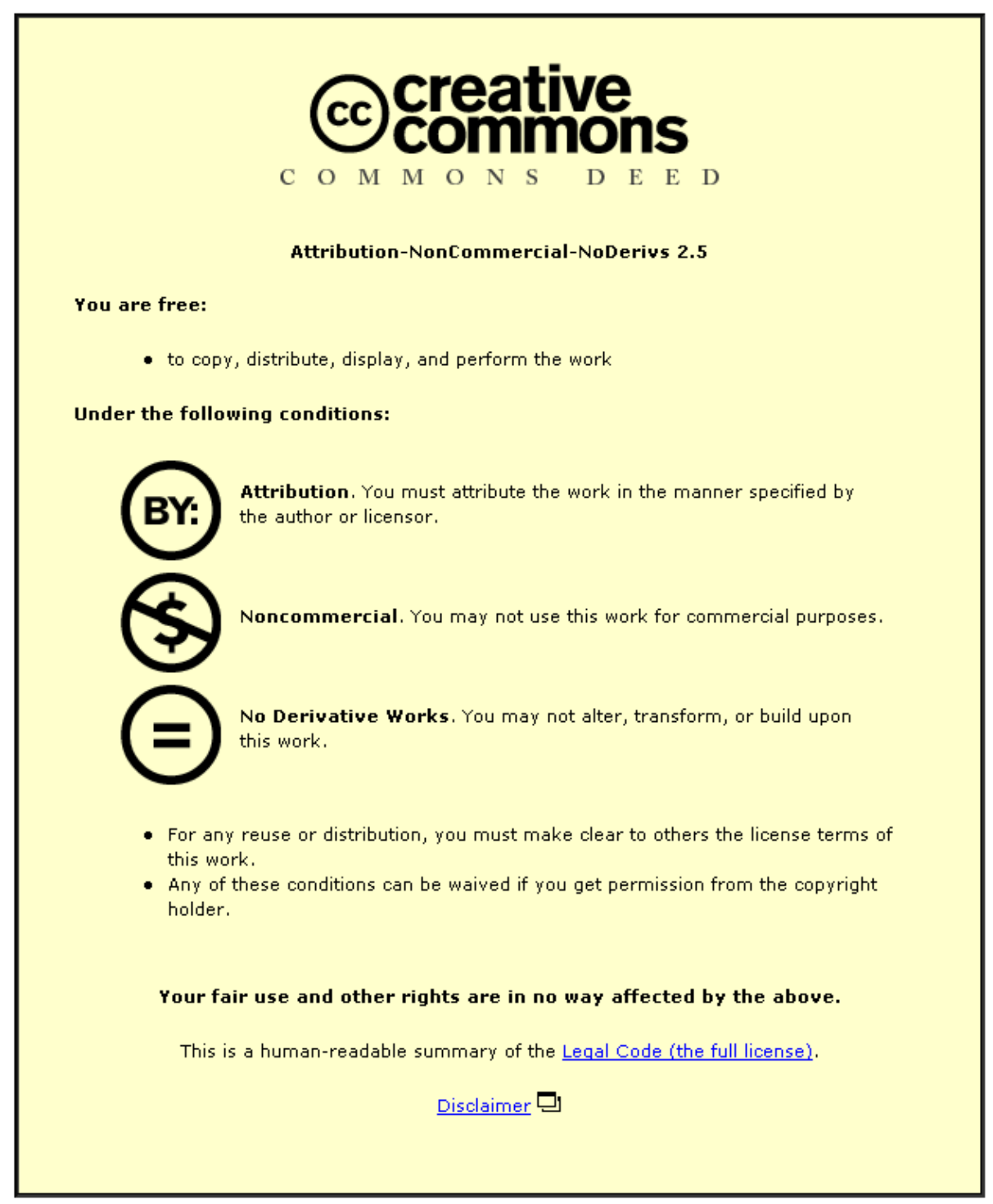

For the full text of this licence, please go to: http://creativecommons.org/licenses/by-nc-nd/2.5/ 


\title{
Optimizing Microneedle Arrays for Transdermal Drug Delivery: Extension to Non-square Distribution of Microneedles
}

\author{
Barrak Al-Qallaf ${ }^{1}$, Diganta Bhusan Das ${ }^{2 \text { * }}$
}

1 Department of Engineering Science, Oxford University, Oxford OX1 3PG, UK

2 Department of Chemical Engineering, Loughborough University, Loughborough LE11 3TU, UK

Accepted for Publication in the journal:

Journal of Drug Targeting

24 July 2008

*Author for correspondence (Email: D.B.Das@lboro.ac.uk) 


\title{
Optimizing Microneedle Arrays for Transdermal Drug Delivery: Extension to Non- square Distribution of Microneedles
}

5

\author{
Barrak Al-Qallaf ${ }^{1}$, Diganta Bhusan Das ${ }^{2 *}$
}

1 Department of Engineering Science, Oxford University, Oxford OX1 3PG, UK

102 Department of Chemical Engineering, Loughborough University

Loughborough LE11 3TU, UK

\begin{abstract}
$\underline{\text { Abstitract }}$
The technology of fabricating microneedle arrays to deliver high molecular weight drugs across skin in a minimally invasive manner is receiving increasing attention. Microneedle arrays with different geometries have been manufactured using materials such as glass, polytaler, metal, etc. However, a framework that can identify the optimum designs of these arrays seems to be lacking. This is important since by optimising the microneedles dimensions (e.g., surface area of the patch, microneedle radius, etc) the permeability of drugs in skin can be increased. To address this issue, this study presents an optimization framework for transdermal delivery of high molecular weight drug from microneedle. The optipization process is based on determining an optimisation function (g) for various microneedles patterns (e.g., square, diamond, triangular, etc). We argue that higher the value of $g$ is the higher the drug permeability in skin is. The outputs of the developed framework have allowed us to identify the optimum design of both solid and hollow microneedles. In particular, the results have been used to predict skin permeability of high moläbular weight using microneedle system. Also, optimum designs based on different classifications of skin thickness (e.g., race, age, etc) for transdermal delivery of drugs are suggested.
\end{abstract}

Keywords:

Micß̄̄needle arrays, Transdermal drug delivery, Optimisation, Mathematical modelling, Mass transfer

*Author for correspondence (Email: D.B.Das@lboro.ac.uk; Tel: 00441509 222509) 


\section{Introduction}

For many years it has been seen that a variety of drugs can be successfully administered throłgh transdermal drug delivery. For example, applications involving delivery of nitroglycerine ointment (Henzl and Loomba, 2003) and nicotine patch (Edelman, 2001) have proven the viability of such transdermal drug delivery systems. However, the range of drugs that are incorporated into the drug delivery systems is often restricted by the barrier function of the skin. The outer layer, or the stratum corneum, is the main obstacle to tran\&8ermal drug delivery when a drug diffuses through the skin (Sivamani et al., 2005). One of main aims in transdermal drug delivery research is to increase the permeability of drug penetrating the skin (Al-Qallaf and Das, 2008a,b). This is because skin permeability is a key parameter that represents the path length of a molecule across a given skin thickness over unit time (Environmental Protection Agency, 1992). One way to resolve these issues is tळ@mploy microneedle arrays as a transdermal delivery system (Lee et al., 2008). They consist of micron-sized projections that pierce the stratum corneum allowing the drugs to bypass the main barrier to diffusion. Studies have shown that the microneedle arrays cause no or little pain and are well tolerated by users, making it preferential to injection by syringe (Nir et al., 2003; Prausnitz et al., 2005; Simonsen et al., 1999). The microneedles can $5 \$$ \$so offer a number of other benefits over other drug delivery methods. For example, many drugs administered via an oral route may be susceptible to poor absorption (Stoeber and Liepmann, 2000) and hence have a low bioavailability (Cross and Roberts, 2004). This is not the case when using microneedles where the drugs only diffuse over a short distance before reaching the blood circulation which enhances the absorption of drugs by the tissue (Az60)and Majlis, 2006; Aggarwal and Johnston, 2004).

The concept behind microneedles was suggested in the 1970's but it was not until the 1990's that their utility was demonstrated experimentally (Roxhed et al., 2007). This was mainly thanks to the advances in the microelectronics industry that allowed the production of r6ficron-scale structures. The first needles to be reported in literature were created by Hashmi et al. (1995) to increase molecular and genetic material uptake in cells. The first study to determine whether microneedles could be used to increase skin permeability was conducted by Henry et al. (1998). They found that the skin permeability to calcein (a model drug) could be increased by over 3 orders of magnitude in vitro. Microneedles have been showo to deliver high molecular weight drugs, DNA, proteins and vaccine (Lee et al., 2008; Pearton et al., 2007; Reed and Lye, 2004). In addition to this, it was found that the use of 
microneedles is painless and does not damage the tissue as the short micro-projections were not long enough to stimulate the nerve endings in the deeper tissue of the skin (Jiang et al., 2007; McAllister et al., 2000). Since these promising early results, developing mic/̋rneedles suitable for pharmaceutical applications has been an active area of research.

It is also interesting to note that since the first fabrication of these microneedles, a variety of designs involving different distributions of the microneedles have been proposed. However, studies aimed at optimizing the dimensions of these microneedles have been limited. An apponach to determine the optimal shape of microneedle by maximizing the buckling load has been presented by Vasquez and Pelesko (2005). A method to optimize the hole locations of various microneedle has been proposed by Khumpuang et al. (2007).

Recently, we have initiated investigations on optimizing the square patch of microneedle arra\$5 (Al-Qallaf and Das, 2008a,b). They have been done by considering the microneedle dimensions (e.g., number of microneedles, microneedle radius, etc) of both solid and hollow microneedles to maximize the drug skin permeability. However, it is realized that since the first fabrication of microneedles a large variety of microneedle distribution have been proposed such as square (Ji et al., 2006; Kim and Lee, 2007), hexagonal (Matriano et al., 2002; Widera et al., 2006), triangular (Perennes et al., 2006) and rectangular (Park et al., 2005). Aggarwal and Johnston (2004) investigated the influence of various patterns (e.g., square, rectangular, etc) on buckling force, bending force and bending stress. Our previous work (Al-Qallaf and Das, 2008a,b) have attempted to study and hence optimize the square patch with a square microneedle distribution to maximize the skin permeability. WhHE the developed framework (Al-Qallaf and Das, 2008a,b) is useful, it seems it is also necessary to develop the wider applications of the framework to non-square distributions of the patterns so as to optimize them for transdermal drug delivery. To address this issue, we extend our previous work (Al-Qallaf and Das, 2008a,b) to consider non-square patterns (i.e., rectangular) as well as the distribution of microneedles such as triangular and diannofd. We optimize and compare the microneedle arrays of both square and rectangular patch to maximize skin permeability of both solid and hollow microneedles. The optimization framework of considering both the microneedle pattern as well as the distributions allows us to identify the optimum pattern and distribution to enhance the performance of microneedles array. It must be pointed out that in the present context 'patten' means the shape of the microneedles array (i.e., square or rectangular) and 
'distribution' means the arrangement of the microneedles inside an array (i.e., triangular or diamond).

In this work, we have also considered the epidermis thickness of various skin thickness clas\$iffocations (e.g., race, sex, etc). In another case, the microneedle length has been considered to evaluate the skin permeability of the optimum models proposed. The outcomes of this work have allowed us to predict and hence relate skin permeability with the diffusion coefficient of various model drugs. The hexagonal pattern is not considered in this paper as we have previously showed that the effective skin permeability is only slightly highler5n the hexagonal pattern than the square pattern (Davidson et al., 2008). This means that there is not much difference between the square and the hexagonal patterns and the square pattern has almost the same influence as the hexagonal pattern.

\section{Methodology}

\subsection{DDloeoretical Model}

To develop the current framework, a simple theoretical in vitro model was adopted using the following equation to calculate skin permeability when using microneedles (McAllister et al., 2003):

$$
\mathrm{K}=\mathrm{f} \frac{\mathrm{D}}{\mathrm{L}_{\mathrm{h}}}
$$

Here,2吕 is the skin permeability of drugs, $\mathrm{f}$ is the fractional skin area after insertion by microneedles, $\mathrm{D}$ is the effective diffusion coefficient of drugs in skin and $\mathrm{L}_{\mathrm{h}}$ is the length of a hole in skin. The hole length $\left(\mathrm{L}_{\mathrm{h}}\right)$ represents either the epidermis thickness $(\mathrm{h})$ in case of solid microneedles or the microneedle length $(\mathrm{L})$ in case of hollow microneedles. This depends on the movement of drug molecules. In the case of solid microneedles the drug moleb0les do not move through the microneedle itself but traverse through various disruptions in the skin thickness (i.e. epidermis) from the patch to blood vessels. In the case of hollow microneedles, the molecules move through the bores of hollow microneedle and this path length represents the microneedle length. The assumptions of this developed framework have been explained in detail previously (Al-Qallaf and Das, 2008a). 135

The fractional skin area in equation (1) when the microneedles are inserted in skin is given as: 
$\mathrm{f}=\mathrm{N}_{\mathrm{t}} \pi \frac{(\mathrm{R}+\mathrm{W})^{2}-\mathrm{R}^{2}}{\mathrm{~A}}$

Here, $\mathrm{N}_{\mathrm{t}}$ is the total number of microneedles for a given patch, $\mathrm{R}$ is the microneedle radius, $\mathrm{W}$ i\$ 40 annular gap width (W) and A is the surface area of the patch. We have adopted equation (2) as our main governing equation for the optimization framework to maximize the skin permeability in equation (1).

The annular gap width (W) is defined as a function of microneedle radius (R) as follows:

$\mathrm{W} \pm 4 \mathrm{~s} R$

Here, $\varepsilon$ is a dimensionless parameter for the ratio of annular gap width over microneedle radius.

\subsection{Formulation of Optimization Function}

In oll\$रrevious study (Al-Qallaf and Das, 2008a,b), we have defined that the microneedles array has a square patch, where the total number of microneedles $\left(\mathrm{N}_{\mathrm{t}}\right)$ is $\mathrm{n}$ by $\mathrm{n}$ (the number of microneedles per row). For the purpose of this work, we substitute equation (3) into (2) and rearrange as follows:

$\mathrm{f}=\pi \frac{\mathrm{N}_{\mathrm{t}} \mathrm{R}^{2}}{\mathrm{~A}} \varepsilon(\varepsilon+2)$

Alsd,55combining equations (1) and (4), the skin permeability for the cases when microneedles are inserted is:

$$
\mathrm{K}=\mathrm{c} \pi \frac{\mathrm{N}_{\mathrm{t}} \mathrm{R}^{2}}{\mathrm{~A}} \frac{\mathrm{D}}{\mathrm{L}_{\mathrm{h}}}
$$

Here, $\mathrm{c}=\varepsilon(\varepsilon+2)$

As $L_{h}, D, c$ and $\pi$ are constants, the problem statement in equation (5) can be reformulated as: 160

$g=\frac{n^{2} R^{2}}{A}$

Where $\mathrm{g}$ is the optimization function derived and $\mathrm{n}^{2}$ is the total number of microneedles provided that the total number of microneedles $\left(\mathrm{N}_{\mathrm{t}}\right)$ equals $\mathrm{n} \times \mathrm{n}$ as explained before. Therefore, the skin permeability when microneedles are inserted can be introduced as:

$\mathrm{K}=16 \overline{\mathrm{g} g} \frac{\mathrm{D}}{\mathrm{L}_{\mathrm{h}}}$ 
Therefore, the skin permeability (K) in equation (5) increases by maximizing the optimization function (g) in equation (7) such that:

$$
\begin{aligned}
& \mathrm{n}_{\text {min }} \leq \mathrm{n} \leq \mathrm{n}_{\text {max }} \\
& \mathrm{R}_{\text {min }} \leq \mathrm{R} \leq \mathrm{R}_{\text {max }} \\
& \left.\mathrm{A}_{\text {min }}\right] \propto \mathrm{A} \leq \mathrm{A}_{\max }
\end{aligned}
$$

It is obvious from equation (7) that g reaches its highest value for maximum values of $n$ and $\mathrm{R}$ and, minimum A. However, we have showed previously the importance of introducing a new constraint as follows (Al-Qallaf and Das, 2008a,b):

$\mathrm{P}_{\mathrm{t}} \geq \alpha \mathrm{R}$

Her $\mathbb{A}, 7 \mathrm{~B}_{\mathrm{t}}$ is the pitch, the distance of centre-to-centre between two adjacent microneedles as shown in Fig. 1 and, $\alpha$ is the aspect ratio of the pitch over microneedle radius so that $\alpha>2.0$ to prevent any overlapping between two adjacent microneedles. We define the pitch as (Al-Qallaf and Das, 2008a,b):

$$
\mathrm{P}_{\mathrm{t}}=\frac{\sqrt{\mathrm{A}}}{\mathrm{n}}
$$

Equagons (10) and (11) are combined to yield a new constraint for optimisation as (AlQallaf and Das, 2008a,b):

$$
\frac{\sqrt{\mathrm{A}}}{\mathrm{n}} \geq \alpha \mathrm{R}
$$

To further study the case of square patch, we investigated the influence of changing the pattæ85by introducing the diamond and triangular patterns as shown in Fig.1. The idea of the microneedles distribution is analogous to the packing of tubes in heat exchangers, where the tubes in the heat exchangers represent the microneedles (Hewitt, 1990; Perry et al., 1984).

The1pgoch of the diamond pattern per row $\left(\mathrm{P}_{\mathrm{tn}}\right)$ or per column $\left(\mathrm{P}_{\mathrm{tm}}\right)$ is given as follows:

$$
\mathrm{P}_{\mathrm{tn}}=\mathrm{P}_{\mathrm{tm}}=0.707 \times \mathrm{P}_{\mathrm{t}}
$$

Therefore, the area of a square array for the diamond pattern is:

$$
A=2 n \times P_{\text {tn }} \times 2 m \times P_{\text {tm }}
$$


Here, $\mathrm{m}$ is the total number of microneedles per column and assuming $\mathrm{n}$ equals $\mathrm{m}$ since the patch9Бas a square shape. By combing equations (10), (13) and (14), the new constraint of the diamond pattern is:

$\frac{\sqrt{\mathrm{A}}}{1.414 \times \sqrt{\mathrm{n} \times \mathrm{m}}} \geq \alpha \mathrm{R}$

Although $n$ equals $m$ and $P_{t n}$ equals $P_{t m}$, the ranges of both $P_{t n}$ and $P_{t m}$ are different according to the reported values in the literatures. Therefore, we define the total number of mic200eedles and pitch per either row or column as $n$ and $m$ so that the optimisation program can iterate the input parameters depending on the selected range for $\mathrm{n}$ and $\mathrm{m}$.

In case of the triangular pattern, the pitch for each per row $\left(\mathrm{P}_{\mathrm{tn}}\right)$ is given as follows:

$\mathrm{P}_{\mathrm{tn}}=0.866 \times \mathrm{P}_{\mathrm{t}}$

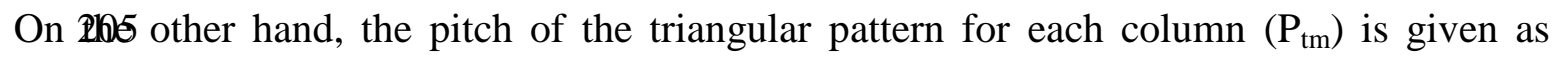
follows:

$\mathrm{P}_{\mathrm{tm}}=0.5 \times \mathrm{P}_{\mathrm{t}}$

By combing equations (10), (14), (16a) and (16b) we find that the area of a square patch for both the triangular and diamond patterns is equal. Therefore, the new constraint of triapgilar pattern is:

$\frac{\sqrt{\mathrm{A}}}{1.316 \times \sqrt{\mathrm{n} \times \mathrm{m}}} \geq \alpha \mathrm{R}$

To expand the scope of this work further, we have included the rectangular patch as shown in Fig. 1. The optimization function (g) of this patch can be introduced as:

$g=\frac{(\mu \times m) R^{2}}{A}$

Here, $\mathrm{n}$ is not necessarily equal to $\mathrm{m}$. The area of a rectangular patch is:

$\mathrm{A}=\mathrm{n} \times \mathrm{P}_{\mathrm{tn}} \times \mathrm{m} \times \mathrm{P}_{\mathrm{tm}}$

Hence, the new constraints for the rectangular patch are given as:

$\frac{\mathrm{A}}{\mathrm{n} \times \mathrm{m} \times \mathrm{P}_{\mathrm{tn}}} \geq \alpha \mathrm{R}$

$\frac{220}{\mathrm{n} \times \mathrm{m} \times \mathrm{P}_{\mathrm{tm}}} \geq \alpha \mathrm{R}$ 
Therefore, the optimization function (g) in equation (18) is maximized by considering the constraint equations (9a-9c) along with the following constraint:

$$
\begin{aligned}
& \mathrm{m}_{\text {min }} \leq \mathrm{m} \leq \mathrm{m}_{\text {max }} \\
& \mathrm{P}_{\text {tn }_{\text {min }}} \leq \mathrm{P}_{\text {tn }} \leq \mathrm{P}_{\text {tn } \text { max }} \\
& \mathrm{P}_{\mathrm{tm}_{\text {min }}^{225}} \leq \mathrm{P}_{\mathrm{tm}} \leq \mathrm{P}_{\mathrm{tm}_{\text {max }}}
\end{aligned}
$$

The values of microneedle pitch $\left(\mathrm{P}_{\mathrm{tn}}\right)$ and $\left(\mathrm{P}_{\mathrm{tm}}\right)$ for all patterns are explained in Table 1.

\subsection{Method of solution}

In this work, an in-house java program is used to solve the optimization equations (7) and (18)2Bor the constraint equations (9a-c), (12), (15), (17) and (20-22c). The input parameters for solving these equations are as shown in Table 2 which are mostly adopted from reported literature. In some cases, we have expanded the microneedle geometries to cover a broader range of parameters. For example, $\mathrm{n}_{\max }$ of rectangular patch has been increased to 20 for both solid and hollow microneedles and, also the aspect ratios $(\alpha)$ of square, diamond and triangtiar patterns of solid microneedles have been extended to 20 as compared to the reported values. On the other hand, the aspect ratios of hollow microneedle for diamond and triangular patterns have been increased to 30 and for square and rectangular patterns to 40. The inconsistency of this expansion is due to the unfulfillment of the geometrical condition of this optimization model. For briefness, the description of the developed frametaork of the optimization algorithm is avoided as it was explained previously (AlQallaf and Das, 2008a,b). It must be added, however, that for a given iteration of the optimisation algorithm, a scale (step size) is defined by the user for each parameter as shown in Table 2.

\section{Reşults and Discussions}

Some typical results of the developed optimization model for the input parameters (Table

2) for both solid and hollow microneedles are listed in Table 3. As stated before, our approach of optimization involves developing a method to maximize the skin permeability to obtain optimum microneedle design of various patterns with different geometries for solia5nd hollow microneedles. Therefore, the purpose of these simulations is to identify both the optimum pattern and distribution of microneedles to enhance the performance of microneedles array. The results presented in Table 3 show that in case of solid and hollow microneedles, the maximum values the optimization function (g) are approximately 0.081 
and 0.13, respectively. As discussed below, various microneedle patterns and their geoßneftries (e.g., number of microneedles per row, microneedle radius, etc) have been optimized and analysed to address their influences in terms of the optimization function (g), and thereby, the design of microneedle. The outcome of the simulations allow us to identify the optimum dimensions of microneedles by reaching the highest values of the optimization function (g). These optimum dimensions are then used in equation (8) to determine the optia60ms skin permeability. This is done by either varying the classification of skin thickness in case of solid microneedles or microneedle length in case of hollow microneedles. Moreover, the optimum dimensions of both solid and hollow microneedles are correlated with the diffusion coefficient to predict various correlations for different microneedles shapes and patterns. The issues related to predicting drug concentration in blo@265ill be discussed in a future paper.

\subsection{Optimization of Surface Area of Patch}

The design of microneedle arrays is constrained by a number of parameters including the surface area of microneedle arrays (Gill and Prausnitz, 2007; Al-Qallaf and Das, 2008a,b; Al-Qzallaf et al., 2007). For the purpose of this section, we studied the surface area of microneedle arrays with a view to optimize this parameter and hence, enhance the drug delivery process. As shown in equations (7) and (18), there is an inverse relationship between the surface areas of square and rectangular patch and, the optimization function (g). We have carried our simulations to present the influence of this inverse relationship for different microneedle patterns for both solid and hollow microneedles (Fig. 2). Based on the optimum results listed in Table 3, our optimization approach suggests that the best microneedle pattern for solid microneedle is either the square or the rectangular patch corresponding to an optimization function (g) of 0.081 and a surface area of $0.15 \mathrm{~cm}^{2}$ and $0.49 \mathrm{~cm}^{2}$, respectively. On the other hand, the best microneedle pattern for hollow mic280edle is the rectangular pattern corresponding to an optimization function (g) of 0.13 and a surface area of $0.18 \mathrm{~cm}^{2}$. The simulations show that the rectangular patterns of both solid and hollow microneedles give the highest values of optimization function (g) and hence, higher skin permeability. The general practical implications of these results, e.g., the suitable patterns for a given scenario (e.g., skin thickness), are discussed in the following sect2805s.

\subsection{Optimization of Microneedle Radius}


The implications of studying the influence of the proportional relationship between the optimization function (g) and microneedle radius as shown in equations (7) and (18) are illustanted in this section. Figure 3 shows the dependence of the optimization function (g) on the microneedles radius (R) of both solid and hollow microneedles for the tested patterns with corresponding optimum surface area of microneedle array as listed in Table 3. We define the optimum value when the highest value of $\mathrm{g}$ function is reached. This is because we are seeking the maximum skin permeability and hence, the maximum values of $g$ funagton. Among the microneedle pattern evaluated, the highest and lowest optimum values of the microneedle radius in case of solid microneedles are $0.01 \mathrm{~cm}$ and $0.0055 \mathrm{~cm}$ for rectangular and diamond patterns, respectively (Fig. 3). Moreover, the highest and the lowest optimum values of the microneedle radii in case of hollow microneedles are 0.0135 $\mathrm{cm}$ and $0.0115 \mathrm{~cm}$ for square and triangular patterns, respectively. Our results suggest that optiBnitaing microneedle radius to maximize the optimization function (g) is valuable for enhancing the optimized skin permeability (K). These results agreed well with a previous experimental result presented by Teo et al. (2005).

\subsection{Optimization of the number of microneedles per row}

The3intsluence of the number of microneedles on the performance of the microneedles array has been addressed previously (Park et al., 2005; Stoeber and Liepmann, 2005). Nevertheless, we believe that it is also necessary to consider how to optimize the total number of microneedles $\left(\mathrm{N}_{\mathrm{t}}\right)$ in a given patch for a given pattern. The implications of changing the optimum number of microneedles of both per row (n) and per column (m) on the $\mathbf{b p}$ flmization function (g) for various microneedle patterns is shown in Fig. 4. It must be pointed out that the total number of microneedles in Fig. 4 are explained in Table 4 for clarification. The optimization function for both solid and hollow microneedles varies almost linearly with the total number of microneedles for all cases of microneedle patterns. The results in Fig. 4 indicate that the highest optimization function in terms of solid micBdrseedles happens for either the square or rectangular patterns, whereas, in terms of hollow microneedles it happens for the rectangular pattern. The optimum designs may offer variety of benefits for designing microneedle geometries for a given purpose, e.g., reducing the cost of fabrication, etc.

\subsection{2ptimization of the Aspect Ratio $(\alpha)$}


In this work, the aspect ratio $(\alpha)$ is defined as the ratio of the center-to-center distance between two microneedles (pitch) to the microneedle radius (R). In general, this parameter should be greater than 2.0 so that an overlapping between any two microneedles does not occur. Further, if the pitch is too small $(<2.0)$, then the needles are placed too close to one anoties which may prevent them from pain free penetration of the skin due to their mechanical strengths and reaching the targeted depth (Miyano et al., 2005). Fig. 5 illustrates the optimum pitch $\left(\mathrm{P}_{\mathrm{t}}\right)$ as a function of aspect ratio $(\alpha)$ for both solid and hollow microneedles of various microneedle patterns. Fig. 5 depicts that in case of rectangular pattern for both solid and hollow microneedles, the aspect ratio has no obvious influence on the 3 Bकtimum pitch. This means that the optimum pitch occurs at the minimum pitch of either per row $\left(\mathrm{P}_{\mathrm{tn}}\right)$ or per column $\left(\mathrm{P}_{\mathrm{tm}}\right)$. On the other hand, in case of other pattern, the optimum pitch for both solid and hollow microneedles varies nonlinearly with the aspect ratio. Moreover, the triangular and diamond patterns of solid and hollow microneedles, respectively, show partially different behaviour than the other patterns types as the highest optiB335m pitch does not occur at the highest aspect ratio. This is clear from Fig. 5 as the highest optimum pitch for the triangular and diamond patterns of solid and hollow microneedles occurs at an aspect value of 12 and 25 instead of 20 and 30, respectively. Fig. 6 reveals how the aspect ratio of solid and hollow microneedles of various microneedle patterns influences the optimization function. As shown in Fig. 6, there is an inverse relat46ship between the optimization function and the aspect ratio for all cases of microneedles patterns for both solid and hollow microneedles except in case of rectangular pattern of solid microneedles. Therefore, for a given microneedle pattern (i.e., rectangular pattern), changing the aspect ratio does not affect the optimization function significantly. Moreover, the optimization function reaches its highest values at the minimum aspect ratio for a4 4 microneedle patters.

\subsection{Effect of the Skin Thickness}

As well known, there is strong evidence that the skin thickness can vary according to age, race, anatomical region and sex (Lee and Hwang, 2002; Fenske and Lober, 1986). Skin thicB5ess therefore can play an important role as a barrier against any injected drugs. In a previous work, we have studied the influence of epidermis thickness of various anatomical regions (Al-Qallaf and Das, 2008a; Al-Qallaf et al., 2007), sex (Al-Qallaf and Das, 2008a), age group and race (Al-Qallaf and Das, 2008b) on skin permeability for various drugs of the square patch. In this work, we evaluate the effects of epidermis thickness for all skin 
thick̄̄̄ess classifications on drug permeation in skin of various patterns. As explained previously, the path length of skin disruption made by solid microneedles represents the effective diffusion length (i.e., thickness of the epidermis) and there is an inverse relationship between the epidermis thickness (h) and skin permeability (K) as shown in equation (1). The dependency of the thickness of epidermis (h) for various age groups (Artz et aB60979) on skin permeability (K) for calcein as a model drug is shown in Fig. 7. The importance of considering the calcein as a model drug is avoided in this work as it was explained previously (Al-Qallaf and Das, 2008a). As shown in Fig. 7, there is a significant increase in the optimized skin permeability for either square or rectangular patterns as compared to the other microneedle patterns. For example, the difference in the optimized skin36ø̄meability for a given microneedle pattern between the epidermis thickness of age group (0-5) and age group (11-15) proves the necessity of considering the skin thickness. Fig. 8 shows the effect of the epidermis thickness of different races (i.e., Korean and Caucasian) on the optimized skin permeability for various microneedle patterns. The square or rectangular pattern shows significant increase when compared with the other micBöneedle patterns for a given race. In all cases of microneedle patterns, the optimized skin permeability of Caucasian race increases approximately 3 times more than Korean race. The evaluations of the optimized skin permeability as a function of skin thickness with respect to various anatomical regions are shown in Fig. 9. Also, in these evaluations, the optimized skin permeability is higher in either square or rectangular pattern than both

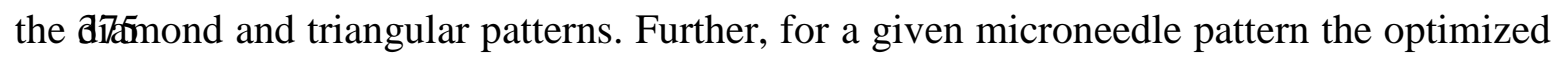
skin permeability is higher in abdomen as compared to back of leg. Fig. 10 presents the implications of changing the skin thickness in terms of sex group for various microneedle patterns. As expected, the optimized skin permeability reaches its highest value at either the square or rectangular pattern for both sex (i.e., female and male). Also, for a given micBroneedle pattern the optimized skin permeability is higher in female than male. These results justified our claim of considering the classification of skin thickness when designing microneedle arrays as well as when fabricating a given microneedle pattern.

\subsection{Effect of the microneedle length}

As 89 Mained previously, the hole length $\left(\mathrm{L}_{\mathrm{h}}\right)$ represents the length of microneedle arrays in case of hollow microneedles. Also, the inverse relationship between the microneedle length (L) and skin permeability as shown in equation (1) motivated us to investigate this parameter as discussed below. To address this point, the influence of this parameter has 
been investigated for various microneedle patterns on the optimized skin permeability for holl390 microneedle arrays. As shown in Fig. 11 different dimensions of microneedle lengths have been compared. As expected, the lower the microneedle length is, the higher the optimized skin permeability across epidermis is. As opposed to the case of solid microneedles, the optimized skin permeability for a given microneedle length reaches its highest value in the rectangular pattern only. The observations of the simulations carried out 30 Bicate that the optimized skin permeability reaches its lowest value in the diamond pattern for both cases, solid and hollow microneedles. The result illustrates that the optimized skin permeability is a function of microneedle length and epidermis thickness in hollow and solid microneedle arrays, respectively and hence the necessity of considering these parameters for the fabrication of microneedle arrays.

400

\subsection{Effect of Skin Permeability}

The optimum microneedles in case of solid microneedles in Table 3 were investigated for different model drugs (McAllister et al., 2003). This investigation is particularly useful to compare the optimized skin permeability of the developed framework presented with respess to various microneedle patterns. Fig. 12 reflects the influences of four microneedles patterns for various model drugs on the optimized skin permeability after applying optimised microneedle systems (solid microneedles). As expected, skin permeability dramatically decreases as the diffusion coefficient of the model drugs decreases. The results also show that skin permeability reaches its highest value when calceint is delivered. This is obviously expected because calcein has the highest diffusion coefficient $\left(6 \times 10^{-6} \mathrm{~cm}^{2} / \mathrm{s}\right)$ (McAllister et al., 2003) among the model drugs and the lowest molecular weight (623 Da) (Nishimura and Lemasters, 2001). Moreover, the influence of various microneedle patterns for these model drugs on the optimized skin permeability after applying optimized microneedle system (hollow microneedles) is presented in Fig. 13. Als $4,1 \bar{n}$ these measurements, the optimized skin permeability decreases by decreasing the diffusion coefficient of the model drugs. The results in both Fig. 12 and Fig. 13 suggest that the microneedle pattern is an important parameter to consider for optimizing and hence, enhancing the transdermal drug delivery using microneedles. Another aim of this work is to formulate a relationship between the optimized skin permeability and diffusion coefficient of theproposed model drugs with various microneedle models. This attempt is presented in Fig. 14 and Fig. 15 for the case of solid and hollow microneedles, respectively. As shown 
in both figures, it seems there is a linear relationship in all microneedle patterns. These correlations are listed in Table 5 for all microneedles patterns types corresponding to their optimum geometries in Table 3. It must be pointed out that these correlations are valid for a diffusion coefficient ranges as $6.5 \times 10^{-8} \leq \mathrm{D} \leq 5 \times 10^{-6} \mathrm{~cm}^{2} / \mathrm{s}$.

\section{Conclusion}

In this study, we have extended an existing optimization approach (Al-Qallaf and Das, 2008a,b) to optimize the pattern and the distribution of microneedles in the patch. In speciBide, we have focused on optimizing the square, diamond, triangular and rectangular distributions of microneedles with a view to optimize their design to maximize the skin permeability for transdermal drug delivery using microneedles. The key results of this paper are that it provides optimum distributions of solid and hollow microneedles with various dimensions of microneedle patterns. The variation of microneedle geometries (e.g., totaß3ømber of microneedles, microneedle radius, pitch, etc) of the optimum design allows one to choose dimensions according to one's need. The results presented in this paper suggest that by reducing the aspect ratio, the skin permeability of drugs can be increased. The simulations carried out indicate that the optimized skin permeability reaches its highest value by adopting the rectangular pattern for both solid and hollow microneedles. Morerer, the optimization microneedle framework introduced here has been applied to study the influence of skin thickness with its classifications (i.e., age anatomical regions, etc) on the optimized skin permeability. We have shown that the skin thickness is major factor that must be considered in designing microneedles (i.e., microneedle patch, microneedle pattern). Altogether, the outcome of this work suggests that for designing mictseedle arrays, optimizing various transport parameters as well as physical dimensions of the system enhance efficiency of transdermal drug delivery techniques. The correlations found in this work for the relationship between the diffusion coefficient and the optimized skin permeability for various microneedle patterns of both solid and hollow microneedles would enable prediction of drug permeation across human skin to deliver low/high mol\&50lar weight drug using microneedles. The optimization strategy introduced in this work could be potentially adopted for medical/clinical applications such as reducing needle radius to exclude bacteria and other foreign particles (Meidan and Michniak, 2004).

\section{Acknowledgment}


The4kifhors would like to thank MOI (Ministry of Interior), Kuwait for their funding of this work.

\section{References}

Al-Qallaf B, Das, DB. 2008a. Optimization of square microneedle arrays for increasing drug4permeability in skin. Chem. Eng. Sci. 63:2523-2535.

Al-Qallaf B, Das DB, 2008b. Optimizing Microneedle Arrays to Increase Skin Permeability for Transdermal Drug Delivery. Annals of the New York Academy of Sciences (in press).

Al-Q6月af B, Das DB, Mori D, Cui ZF. 2007. Modelling transdermal delivery of high molecular weight drugs from microneedle systems. Journal of Phil. Trans. R. Soc. A. 365:2951-2967.

Aggarwal P, Johnston CR. 2004. Geometrical effects in mechanical characterizing of mict010eedle for biomedical applications. Sensors and Actuators B 102:226-234.

Artz CP, Moncrief JA, Pruitt BA. 1979. Burns: a team approach. Philadelphia, USA: WB Saunders. P 22-24.

Azid A, Majlis BY. 2006. Fabrication study of solid microneedles array using HNA. Proceeding of IEEE International Conference on Semiconductor Electronics, ICSE2006, December 6-8, Kuala Lumpur, Malaysia.

Choi JW, Park IB, Ha YM, Jung MG, Lee SW, Lee SH. 2006. Insertion force estimation of vari $₫ 8$ microneedle array-type structures fabricated by a Microstereolithography Apparatus, In: Proceedings of International Joint Conference, October 18-21, Bexco, Pusan, Korea.

Cross SE, Roberts MS. 2004. Physical Enhancement of Transdermal Drug Application: Is DeliAdy Technology Keeping up with Pharmaceutical Development?. Current Drug Delivery 1:81-91.

Davidson A, Al-Qallaf B, Das DB. 2008. Transdermal Drug Delivery by Coated Microneedles: Geometry Effects on Effective Skin Thickness and Drug Permeability. Chem9ideal Engineering Research and Design (doi:10.1016/j.cherd.2008.06.002). 
Edelman SV. 2001. Watching your glucose with the GlucoWatch. Diabetes Technol Ther. 3: 283-284.

Envï\$斤nmental Protection Agency, 1992. Risk assessment forum. Guideline for exposure $\begin{array}{llll}\text { assessment (FRL-4129-5). Washington, } & \text { DC }\end{array}$ (http://www.epa.gov/ncea/raf/pdfs/exposure.pdf).

Fenske NA, Lober CW. 1986. Structural and functional changes of normal aging skin. Joul50 of the American Academy of Dermatology 48: 571-585.

Gill HS, Prausnitz MR. 2007. Coated microneedles for transdermal delivery. Journal of Controlled Release 117: 227-237.

Han50\$, Hyun DH, Park HH, Lee SSL, Kim CH, Kim CG, 2007. A novel fabrication process for out-of-plane microneedle sheets of biocompatible polymer. J Micromech Microeng 17: 1184-1191.

Hashmi S, Ling P, Hashmi G, Reed M, Gaugler R, Trimmer W. 1995. Genetic transflotmation of nematodes using arrays of micromechanical piercing structures. Bio Techniques 19: 766-770.

Henzl MR, Loomba PK. 2003. Transdermal Delivery of Sex Steroids for Hormone Replacement Therapy and Contraception: A Review of Principles and Practice. J Reprod Мењ14: 525-540.

Henry S, McAllister DV, Allen MG, Prausnitz MR. 1998. Microfabrication microneedles: A novel approach to transdermal drug delivery. Journal of Pharmaceutical Sciences 87(8), 922-925.

520

Hewitt GF. 1990. Hemisphere handbook of hear exchanger design., New York, USA: Hemisphere. 
Ji J, Tay FEH, Miao J. 2006. Microfabricated Silicon Microneedle Array for Transdermal Drugd马elivery. Journal of Physics, Conference Series 34:1127-1131.

Jiang J, Gill HS, Ghate D, McCarey BE, Patel SR, Edelhauser HF, Prausnitz MR. 2007. Coated Microneedles for Drug Delivery to the Eye. Investigative Ophthalmology \& Visual Science,48(9): 4038-4043.

530

Kaushik S, Hord AH, Denson DD, McAllister DV, Smitra S, Allen MG, Prausnitz MR. 2001. Lack of pain associated with microfabricated microneedles. Anesthesia and Analgesia 92: 502-504.

Khű̋p̧uang S, Horade M, Fujioka K, Sugiyama S. 2006. Microneedle fabrication using the plane pattern to cross-section transfer method. Smart Mater Struct 15:600-606.

Khumpuang S, Horade M, Fujioka K, Kazuya F, Sugiyama S. 2007. Geometrical strengthening and tip-sharpening of a microneedle array fabricated by X-ray lithography.

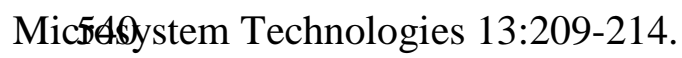

Kim K, Lee JB. 2007. High aspect ratio tapered hollow metallic microneedle arrays with microfluidic interconnector. Microsystem Technologies 13:231-235.

Lee54,5Hwang K. 2002. Skin thickness of Korean adults. Surgical and Radiologic Anatomy 24:183-189.

Lee JW, Park JH, Prausnitz MR. 2008. Dissolving microneedles for transdermal drug delivery. Biomaterials, Doi:10.1016/j.biomaterials.2007.12.048.

550

Martanto W, Davis SP, Holiday NR, Wang J, Gill HS, Prausnitz MR. 2004. Transdermal Delivery of Insulin Using Microneedles in Vivo, Pharmaceutical Research 21: 947-952.

Matriano JA, Cormier M, Johnson J, Young WA, Buttery M, Nyam K, Daddona PE. 2002

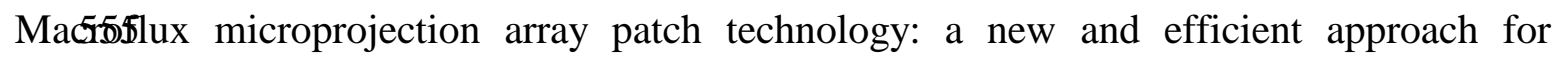
intracutaneous immunization. Pharmaceutical Research 19(1):63-70. 
McAllister DV, Allen MG, Prausnitz MR. 2000. Microfabricated microneedles for gene and drug delivery. Annu Rev Biomed Eng 2: 289 -313.

560

McAllister DV, Wang PM, Davis SP, Park JH, Canatella PJ, Allen MG, Prausnitz MR, 2003. Microfabricated needles for transdermal delivery of macromolecules and nanoparticles: fabrication methods and transport studies. Proceedings of the National Academy of Sciences of the United States of America 100: 13755-13760. 565

Meidan VM, Michniak BB. 2004. Emerging technologies in transdermal therapeutics. Am J Ther 11:312-316.

Miyano T, Tobinaga Y, Kanno T, Matsuzaki Y, Takeda H, Wakui M, Hanada K. 2005. Sugä70nicro needles as transdermic drug delivery systems. Biomedical Microdevices 7(3): 185-188.

Nir Y, Paz A, Sabo E, Potasaman I. 2003.Fear of injection in young adults: prevalence and associations. Am J Trop Med Hyg 68(3): 341-344.

575

Nishimura Y, Lemasters JJ. 2001. Glycine blocks opening of a death channel in cultured hepatic sinusoidal endothelial cells during chemical hypoxia. Cell Death \& Differentiation 8:850-858.

Park80H, Allen MG, Prausnitz MR. 2005. Biodegradable polymer microneedles: fabrication, mechanics and transdermal drug delivery. Journal of Controlled Release 104: 51-66.

Park JH, Yoon YK, Choi SO, Prausnitz MR, Allen MG. 2007. Tapered conical polymer

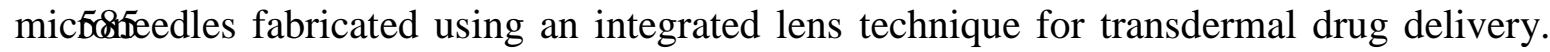
IEEE Transactions on Biomedical Engineering 54(5): 903-913.

Pearton M, Allender C, Brain K, Anstey A, Gateley C, Wilke N, Morrissey A, Birchall J. 2007. Gene delivery to the epidermal cells of human skin explants using microfabricated miç̄oneedles and hydrogel formulations. Pharmaceutical Research, Doi:10.1007/s11095007-9360-y. 
Perennes F, Marmiroli B, Matteucci M, Tormen M, Vaccari L, Fabrizio ED. 2006. Sharp beveled tip hollow microneedle arrays fabricated by LIGA and 3D soft lithography with polyşryl alcohol. J Micromech Microeng 16: 473-479.

Perry RH, Green DW, Maloney JO. 1984. Perry's chemical engineers' handbook. $6^{\text {th }}$ Edition, New York, USA: McGraw-Hill.

Pral6@0tz M, Mikszta J, Raeder-Devens. 2005. Microneedles. In E.W. Smith and H.I. Maibach (eds.), Penetration Enhancers, CRS. Boca Raton, FL, pp. 239-255.

Reed ML, Lye WK. 2004. Microsystems for drug and gene delivery. Proceedings of the IEEE 92(1):56-75.

605

Roxhed N, Gasser TC, Griss P. 2007. Penetration-enhanced ultrasharp microneedles and prediction on skin interaction for efficient transdermal drug delivery. Journal of Microelectromechanical systems 16(6):1429-1440.

Shilfita M, Hasada T, Sato K. 2006. Fabrication of a hollow needle structure by dicing wet etching and metal deposition. J Micromech Microeng 16: 2230-2239.

Sivamani RK, Stoeber B, Wu GC, Zhai H, Liepmann D, Maibach H. 2005. Clinical microneedle injection of methyl nicotinate: stratum corneum penetration. Skin Research and 6lechnology 11: 152-156.

Simonsen L, Kane A, Lloyd J, Zaffran M, Kane M. 1999. Unsafe injections in the developing world and transmission of bloodborne pathogens: a review, Bull. World Health Organization 77(10): 789-800.

620

Stoeber B, Liepmann D. 2005. Arrays of hollow out-of-plane microneedles for drug delivery. J Microelect Systems 14(3): 472-479. 
Stoeber B, Liepmann D. 2000. Fluid injection through out-of-plane Microneedles, Pro@erings of the 1st Annual International IEEE-EMBS Special Topic Conference on Microtechnologies in Medicine and Biology, Lyon, France, October 12-14, pp. 224-228.

Teo MAL, Shearwood C, Ng KC, Lu J, Moochhala S. 2005. In vitro and in vivo characterization of MEMS microneedles. Biomedical Microdevices 7(1): 47-52.

630

Vasquez PA, Pelesko JA. 2005. A variation approach to microneedle design. Proceedings of the International Conference on MEMS, NANO and Smart Systems (ICMENS), Banff, Alberta, Canada, July 24-29, pp. 383-386.

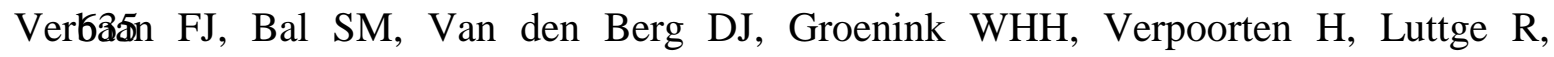
Bouwstra JA. 2007. Assembled microneedle arrays enhance the transport of compounds varying over a large range of molecular weight across human dermatomed skin. Journal of Controlled Release 117: 238-245.

Wide40 G, Johnson J, Kim L, Libiran L, Nyam K, Daddona P, Cormier M. 2006. Effect of delivery parameters on immunization to ovalbumin following intracutaneous administration by a coated microneedle array patch system. Vaccine 24:1653-1664.

Wu XM, Todo H, Sugibayashi K. 2007. Enhancement of skin permeation of high molecular compresinds by a combination of microneedle pretreatment and iontophoresis. Journal of Controlled Release 118: 189-195.

Xie Y, Xu B, Gao Y. 2005. Controlled transdermal delivery of model drug compounds by MEMS microneedle array. Nanomedicine: Nanotechnology, Biology, and Medicine 1; 184190650 
Table 1. The values of microneedle pitch for various patterns and types. Here, 'pattern' means the distribution of the microneedles inside an array and 'type' means the shape of the pattern.
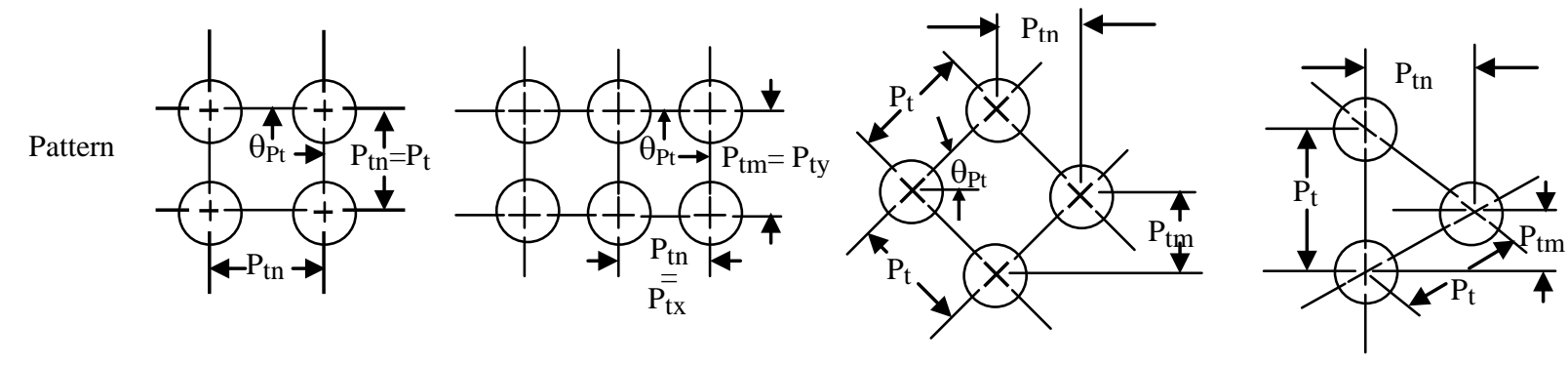

\begin{tabular}{|c|c|c|c|c|}
\hline Type & Square & Rectangular & Diamond & Triangular \\
\hline$\theta_{\mathrm{Pt}}$ & $90^{\circ}$ & $90^{\circ}$ & $45^{\circ}$ & $30^{\circ}$ \\
\hline$P_{\text {tn }}$ & $\mathrm{P}_{\mathrm{t}}$ & $\mathrm{P}_{\mathrm{tx}}$ & $0.707 \mathrm{P}_{\mathrm{t}}$ & $0.866 \mathrm{P}_{\mathrm{t}}$ \\
\hline $\mathrm{P}_{\mathrm{tm}}$ & $\mathrm{P}_{\mathrm{t}}$ & $P_{\text {ty }}$ & $0.707 \mathrm{P}_{\mathrm{t}}$ & $0.5 \mathrm{P}_{\mathrm{tn}}$ \\
\hline
\end{tabular}

655 
Table 2. The input geometrical parameters used in this work for optimizing solid and hollow microneedles arrays

\begin{tabular}{|c|c|c|c|c|c|}
\hline \multirow[b]{2}{*}{ Parameters } & \multicolumn{2}{|c|}{$\begin{array}{l}\text { Rectangular } \\
\text { Pattern }\end{array}$} & \multicolumn{2}{|c|}{$\begin{array}{l}\text { Square/Diamond/Triangular } \\
\text { Pattern }\end{array}$} & \multirow[b]{2}{*}{$\begin{array}{c}\text { Scaling } \\
\text { Parameters }\end{array}$} \\
\hline & Solid & Hollow & Solid & Hollow & \\
\hline $\mathrm{N}$ & $10^{\mathrm{D}} \leq \mathrm{n} \leq 20^{\mathrm{E}}$ & $4^{\mathrm{H}} \leq \mathrm{n} \leq 20^{\mathrm{A}}$ & $3^{\mathrm{I}} \leq \mathrm{n} \leq 10^{\mathrm{C}}$ & $4^{\mathrm{M}} \leq \mathrm{n} \leq 10^{\mathrm{N}}$ & 1 \\
\hline$M$ & - & - & $4^{\mathrm{I}} \leq \mathrm{n} \leq 20^{\mathrm{C}}$ & $8^{\mathrm{M}} \leq \mathrm{n} \leq 20^{\mathrm{N}}$ & 1 \\
\hline $\mathrm{R}$ & $0.0025^{\mathrm{B}} \leq \mathrm{R} \leq 0.0075^{\mathrm{D}}$ & $0.004^{\mathrm{A}} \leq \mathrm{R} \leq 0.015^{\mathrm{G}}$ & $0.005^{\mathrm{J}} \leq \mathrm{R} \leq 0.01^{\mathrm{K}}$ & $0.005^{\mathrm{M}} \leq \mathrm{R} \leq 0.0125^{\mathrm{N}}$ & 0.0005 \\
\hline $\mathrm{A}$ & $0.04^{\mathrm{D}} \leq \mathrm{A} \leq 0.81^{\mathrm{C}}$ & $0.04^{\mathrm{D}} \leq \mathrm{A} \leq 0.56^{\mathrm{F}}$ & $0.03^{\mathrm{K}} \leq \mathrm{A} \leq 1.6^{\mathrm{L}}$ & $0.02^{\mathrm{M}} \leq \mathrm{A} \leq 0.64^{\mathrm{N}}$ & 0.01 \\
\hline $\mathrm{A}$ & $2.7^{\mathrm{D}} \leq \alpha \leq 12^{\mathrm{C}}$ & $3.1^{\mathrm{A}} \leq \alpha \leq 25^{\mathrm{F}}$ & $3.5^{\mathrm{K}} \leq \alpha \leq 40^{\mathrm{J}}$ & $3.2^{\mathrm{N}} \leq \alpha \leq 16^{\mathrm{N}}$ & - \\
\hline $\mathrm{P}_{\mathrm{tn}}$ & - & - & $0.035^{\mathrm{K}} \leq \mathrm{P}_{\mathrm{tn}} \leq 0.2^{\mathrm{J}}$ & $0.03^{\mathrm{M} \leq \mathrm{P}_{\mathrm{tn}} \leq 0.04^{\mathrm{N}}}$ & 0.001 \\
\hline $\mathrm{P}_{\mathrm{tm}}$ & - & - & $0.035^{\mathrm{K}} \leq \mathrm{P}_{\mathrm{tm}} \leq 0.2^{\mathrm{J}}$ & $0.03^{\mathrm{M}} \leq \mathrm{P}_{\mathrm{tn}} \leq 0.08^{\mathrm{N}}$ & 0.001 \\
\hline
\end{tabular}

$\mathrm{n}$ : 66 ber of microneedles per row; m: number of microneedles per column; R: microneedle radius; A: surface area of microneedles array; $\alpha$ : the aspect ratio of pitch over radius; $\mathrm{P}_{\mathrm{tn}}$ : the pitch in $\mathrm{x}$ direction, the distance between two adjacent microneedles per row and $\mathrm{P}_{\mathrm{tm}}$ : the pitch in $\mathrm{y}$ direction, the distance between two adjacent microneedles per column.

${ }^{\mathrm{A}}$ Kafishlik et al. (2001), ${ }^{\mathrm{B}}$ Shikida et al. (2006), ${ }^{\mathrm{C}}$ Park et al. (2005), ${ }^{\mathrm{D}}$ Teo et al. (2005), ${ }^{\mathrm{E}}$ Xie et al. (2005), ${ }^{\mathrm{F}} \mathrm{Wu}$ et al. (2007), ${ }^{\mathrm{G}}$ Khumpuang et al. (2007), ${ }^{\mathrm{H}}$ Verbaan et al. (2007), ${ }^{\mathrm{I}} \mathrm{Choi}$ et al. (2006), ${ }^{\mathrm{J}} \mathrm{Han}$ et al. (2007), ${ }^{\mathrm{K}}$ Miyano et al. (2005), ${ }^{\mathrm{L}}$ Martanto et al. (2004), ${ }^{\mathrm{M}}$ Khumpuang et al. (2006) and ${ }^{\mathrm{N}}$ Park et al. (2007). 
Table 3. The optimum parameters found using the developed framework for both solid and hollow microneedles for various patterns.

\begin{tabular}{|c|c|c|c|c|c|c|c|c|}
\cline { 2 - 9 } \multicolumn{1}{c|}{} & \multicolumn{4}{c|}{ Solid Microneedles } & \multicolumn{4}{c|}{ Hollow Microneedles } \\
\hline Pattern & Array & $\mathrm{R}$ & $\mathrm{A}$ & $\mathrm{g}$ & Array & $\mathrm{R}$ & $\mathrm{A}$ & $\mathrm{g}$ \\
\hline Square & $17 \times 17$ & 0.0065 & 0.15 & 0.081 & $15 \times 15$ & 0.0135 & 0.42 & 0.098 \\
\hline Diamond & $16 \times 16$ & 0.0055 & 0.19 & 0.41 & $11 \times 11$ & 0.011 & 0.3 & 0.049 \\
\hline Triangular & $12 \times 12$ & 0.006 & 0.11 & 0.047 & $9 \times 9$ & 0.0115 & 0.19 & 0.056 \\
\hline Rectangular & $20 \times 20$ & 0.01 & 0.49 & 0.081 & $10 \times 15$ & 0.0125 & 0.18 & 0.130 \\
\hline
\end{tabular}


Table 4. The total number of microneedles in an array for various optimum microneedle arrays.

\begin{tabular}{|c|c|c|c|c|c|c|c|c|c|c|c|}
\hline \multicolumn{6}{|c|}{ Solid Microneedles } & \multicolumn{6}{|c|}{ Hollow Microneedles } \\
\hline \multirow{12}{*}{ 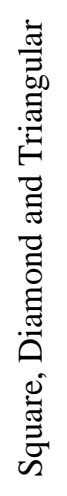 } & Array & $\mathrm{N}_{\mathrm{t}}$ & \multirow{19}{*}{ 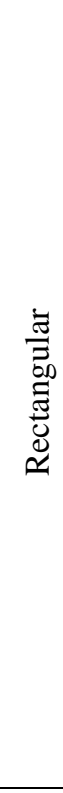 } & Array & $\mathrm{N}_{\mathrm{t}}$ & \multirow{18}{*}{$\vec{E}$} & Array & $\mathrm{N}_{\mathrm{t}}$ & \multirow{18}{*}{ 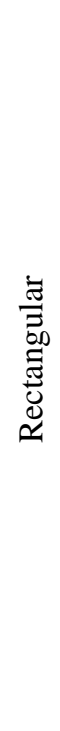 } & Array & $\mathrm{N}_{\mathrm{t}}$ \\
\hline & $10 \times 10$ & 100 & & $3 \times 19$ & 57 & & $4 \times 4$ & 16 & & $4 \times 8$ & 32 \\
\hline & $11 \times 11$ & 121 & & $4 \times 6$ & 24 & & $5 \times 5$ & 25 & & $5 \times 18$ & 90 \\
\hline & $12 \times 12$ & 144 & & $5 \times 8$ & 40 & & $6 \times 6$ & 36 & & $6 \times 11$ & 66 \\
\hline & $13 \times 13$ & 169 & & $6 \times 16$ & 96 & & $7 \times 7$ & 49 & & $7 \times 19$ & 133 \\
\hline & $14 \times 14$ & 196 & & $7 \times 15$ & 105 & & $8 \times 8$ & 64 & & $8 \times 10$ & 80 \\
\hline & $15 \times 15$ & 225 & & $8 \times 15$ & 120 & & $9 \times 9$ & 81 & & $9 \times 12$ & 108 \\
\hline & $16 \times 16$ & 256 & & $9 \times 19$ & 171 & & $10 \times 10$ & 100 & & $10 \times 15$ & 150 \\
\hline & $17 \times 17$ & 289 & & $10 \times 13$ & 130 & & $11 \times 11$ & 121 & & $11 \times 15$ & 165 \\
\hline & $18 \times 18$ & 324 & & $11 \times 20$ & 220 & & $12 \times 12$ & 144 & & $12 \times 18$ & 216 \\
\hline & $19 \times 19$ & 361 & & $12 \times 19$ & 228 & & $13 \times 13$ & 169 & & $13 \times 14$ & 182 \\
\hline & $20 \times 20$ & 400 & & $13 \times 5$ & 195 & & $14 \times 14$ & 196 & & $14 \times 19$ & 266 \\
\hline & & & & $14 \times 18$ & 252 & & $15 \times 15$ & 225 & & $15 \times 20$ & 300 \\
\hline & & & & $15 \times 19$ & 285 & & $16 \times 16$ & 256 & & $16 \times 13$ & 208 \\
\hline & & & & $16 \times 4$ & 64 & & $17 \times 17$ & 289 & & $17 \times 20$ & 340 \\
\hline & & & & $17 \times 12$ & 204 & & $18 \times 18$ & 324 & & $18 \times 17$ & 306 \\
\hline & & & & $18 \times 19$ & 342 & & $19 \times 19$ & 361 & & $19 \times 17$ & 323 \\
\hline & & & & $19 \times 6$ & 114 & & $20 \times 20$ & 400 & & $20 \times 20$ & 400 \\
\hline & & & & $20 \times 20$ & 400 & & & & & & \\
\hline
\end{tabular}


Table 5. The correlations of various microneedles patterns for both solid and hollow microneedles corresponding to their optimum dimensions in Table 3.

\begin{tabular}{|c|c|c|}
\hline \multirow{2}{*}{ Mattern } & Solid & Hollow \\
\hline Square & $\mathrm{K}=1.618 \times \mathrm{D}-0.0008$ & $\mathrm{~K}=1.5519 \times \mathrm{D}+0.0007$ \\
\hline Diamond & $\mathrm{K}=0.8125 \times \mathrm{D}-0.0029$ & $\mathrm{~K}=0.776 \times \mathrm{D}+0.0003$ \\
\hline Triangular & $\mathrm{K}=0.936 \times \mathrm{D}+0.0007$ & $\mathrm{~K}=0.8959 \times \mathrm{D}+0.0014$ \\
\hline Rectangular & $\mathrm{K}=1.622 \times \mathrm{D}+0.0002$ & $\mathrm{~K}=2.0806 \times \mathrm{D}-0.0054$ \\
\hline
\end{tabular}

Where $\mathrm{K}$ is the optimized skin permeability $(\mathrm{cm} / \mathrm{s})$ and $\mathrm{D}$ is the diffusion coefficient of various drugs (i.e., calcein, insulin, BSA (bovine serum albumin), nano25 and nano50 (nanosphere particles with radii of $25 \mathrm{~nm}$ and $50 \mathrm{~nm}$, respectively) in skin $\left(\mathrm{cm}^{2} / \mathrm{s}\right)$. 


\section{List of Figures:}

Figure 1. The schematic diagrams (top view) of: (a) square pattern with a square patch microneedle array, (b) diamond/triangular pattern with a square patch microneedle array and (c) rectangular pattern with a rectangular patch microneedle array. Here $\mathrm{R}$ is the radius of microneedles, $\mathrm{P}_{\mathrm{t}}$ is the pitch in $\mathrm{x}$ or $\mathrm{y}$ direction of square pattern, $\mathrm{P}_{\mathrm{tn}}$ and $\mathrm{P}_{\mathrm{tm}}$ are the pitch in $\mathrm{x}$ and $\mathrm{y}$ direction of diamond, triangular and rectangular pattern, respectively.

Figure 2. The relation between optimization function (g) and the microneedle surface area (A) of solid (dark markers) and hollow (blank markers) microneedles of various patterns with their optimum values in Table 3 for aspect ratio $(\alpha)$ of solid and hollow microneedles is 3.5 and 3.2, respectively.

Figure 3. The relations between optimization function (g) and the microneedle radius (R) of solid (dark markers) and hollow (blank markers) microneedles of various patterns with their optimum values in Table 3 for aspect ratios $(\alpha)$ of solid and hollow microneedles is 3.5 and 3.2, respectively.

Figure 4. The relation between the optimization function (g) and the optimum total number of microneedles $\left(\mathrm{N}_{\mathrm{t}}\right)$ in Table 4 for solid (dark markers) and hollow (blank markers) microneedles of various patterns for aspect ratio $(\alpha)$ of solid and hollow microneedles is 3.5 and 3.2, respectively.

Figure 5. Influence of the aspect ratio of pitch over microneedle radius $(\alpha)$ of solid (dark markers) and hollow (blank markers) microneedles on the optimum pitch $\left(\mathrm{P}_{\mathrm{t}}\right)$ for various patterns.

Figure 6. Influence of the aspect ratio of pitch over microneedle radius $(\alpha)$ of solid (dark markers) and hollow (blank markers) microneedles on our optimization function (g) for various patterns. 
Figure 7. Influence of epidermis thickness (h) of solid microneedles for the optimum microneedles array of various patterns listed in Table 3 for various groups age (Artz et al., 1979) for a given anatomical region (i.e., medial thigh) on the optimized skin permeability (K).

Figure 8. Influence of epidermis thickness (h) of solid microneedles for the optimum microneedles array of various patterns listed in Table 3 for different races (Lee and Hwang, 2002) for a given anatomical region (i.e., chest) on the optimized skin permeability (K).

Figure 9. Influence of epidermis thickness (h) of solid microneedles for the optimum microneedles array of various patterns listed in Table 3 for different anatomical regions (Lee and Hwang, 2002) for a given sex (i.e., male) on the optimized skin permeability (K).

Figure 10. Influence of epidermis thickness (h) of solid microneedles for the optimum microneedles array of various patterns listed in Table 3 for different sex (Lee and Hwang, 2002) for a given anatomical region (i.e., sole) on the optimized skin permeability (K).

Figure 11. Influence of microneedle length (L) of hollow microneedles for the optimum microneedles array of various patterns listed in Table 3 on the optimized skin permeability (K).

Figure 12. Influence of applying our optimization model for solid microneedles of the optimum microneedles listed in Table 3 on the optimized skin permeability (K) for different drugs (i.e., insulin is hexameric insulin, nano(25) and nano(50) are nanosphere particles with molecular radii of $25 \mathrm{~nm}$ and $50 \mathrm{~nm}$, respectively).

Figure 13. Influence of applying our optimization model for hollow microneedles of the optimum microneedles listed in Table 3 on the optimized skin permeability (K) for different drugs (i.e., insulin is hexameric insulin, 
nano(25) and nano(50) are nanosphere particles with molecular radii of $25 \mathrm{~nm}$ and $50 \mathrm{~nm}$, respectively).

Figure 14. Relationship between the optimized skin permeability (K) and diffusion coefficient (D) of the optimum solid microneedles listed in Table 3 for various drugs (i.e., calcein, insulin, BSA (bovine serum albumin), nano25 and nano50 (nanosphere particles with radii of 25 $\mathrm{nm}$ and $50 \mathrm{~nm}$, respectively)).

Figure 15. Relationship between the optimized skin permeability (K) and diffusion coefficient (D) of the optimum hollow microneedles listed in Table 3 for various drugs (i.e., calcein, insulin, BSA (bovine serum albumin), nano25 and nano50 (nanosphere particles with radii of 25 $\mathrm{nm}$ and $50 \mathrm{~nm}$, respectively)). 


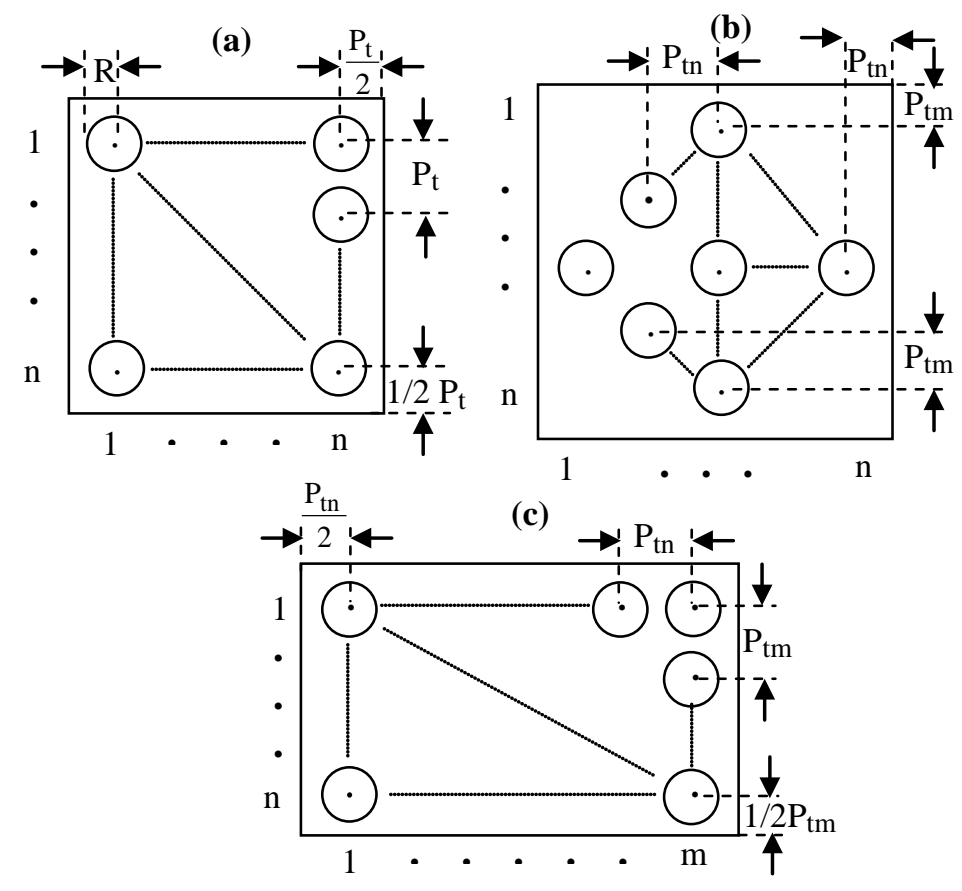

Figure 1. 


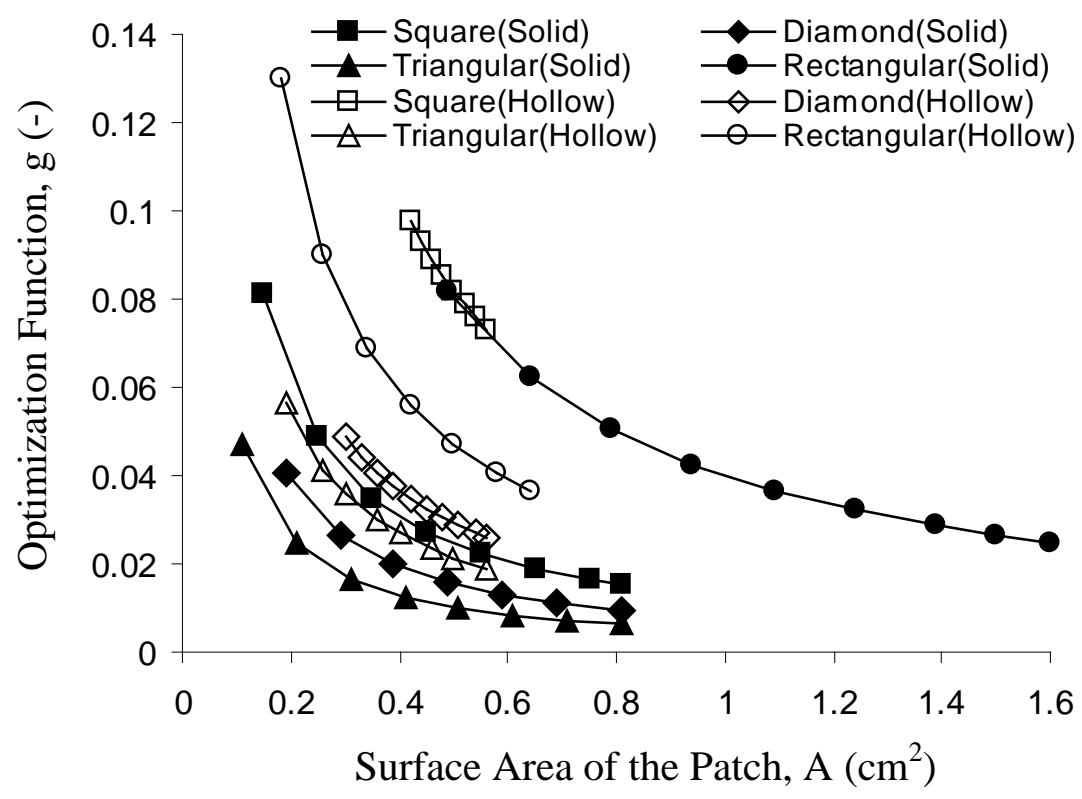

Figure 2. 


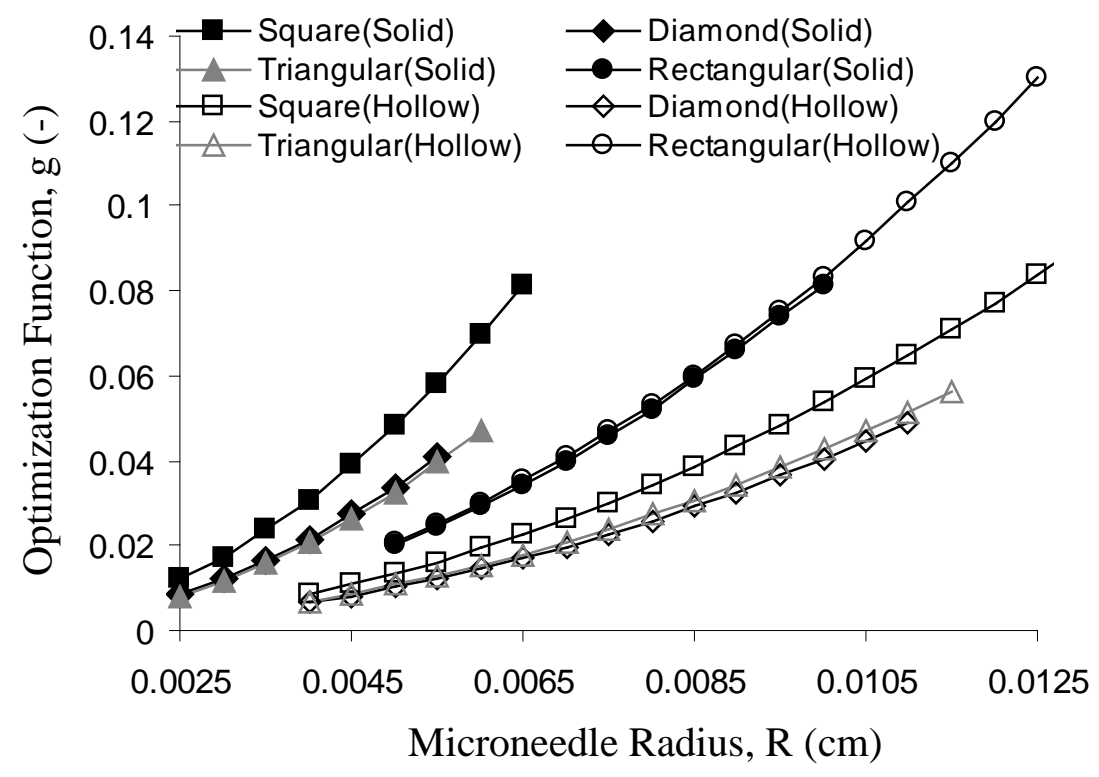

Figure 3. 


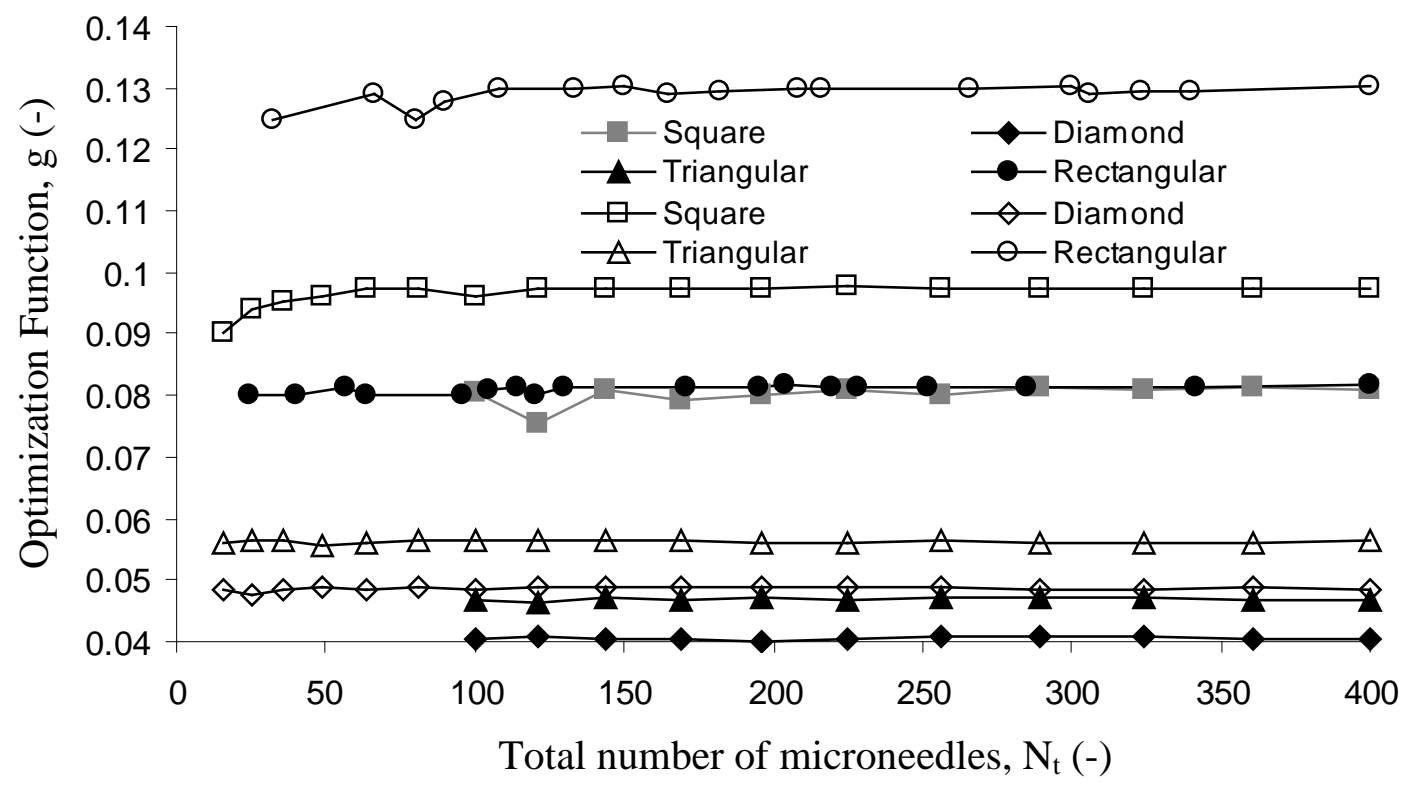

Figure 4. 


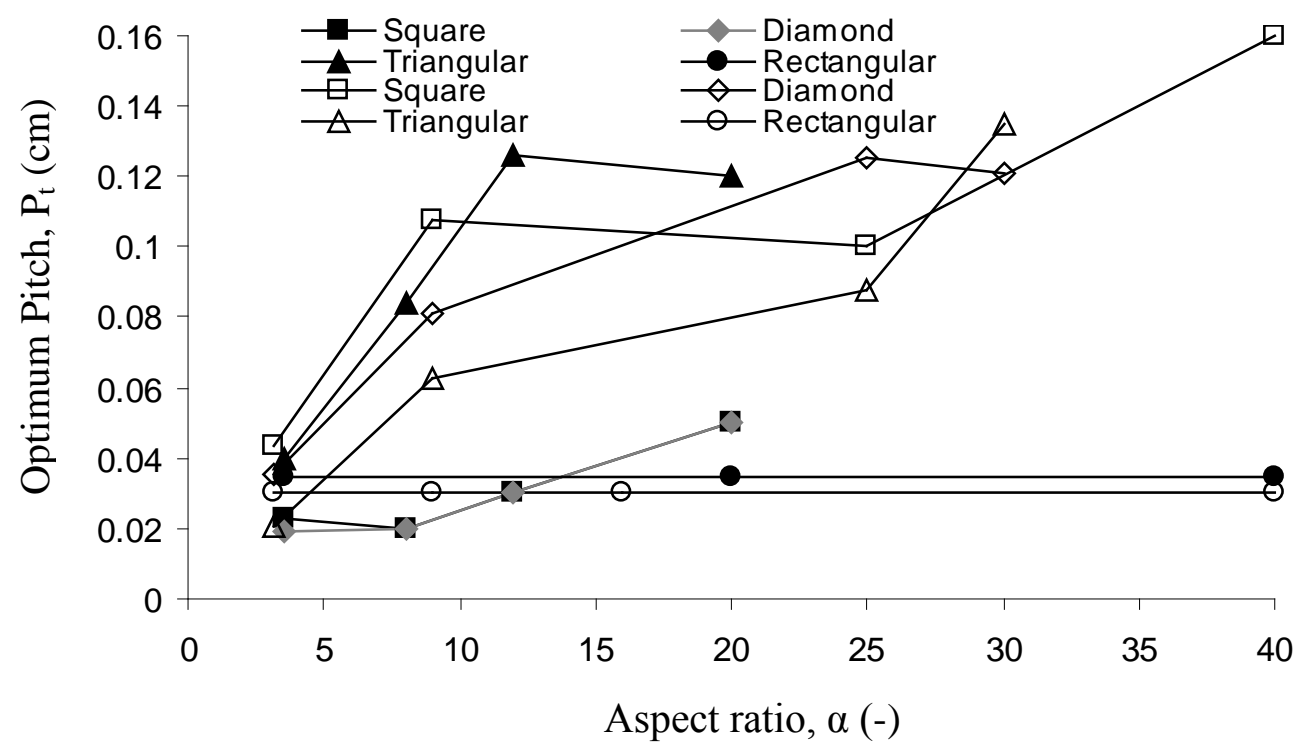

Figure 5. 


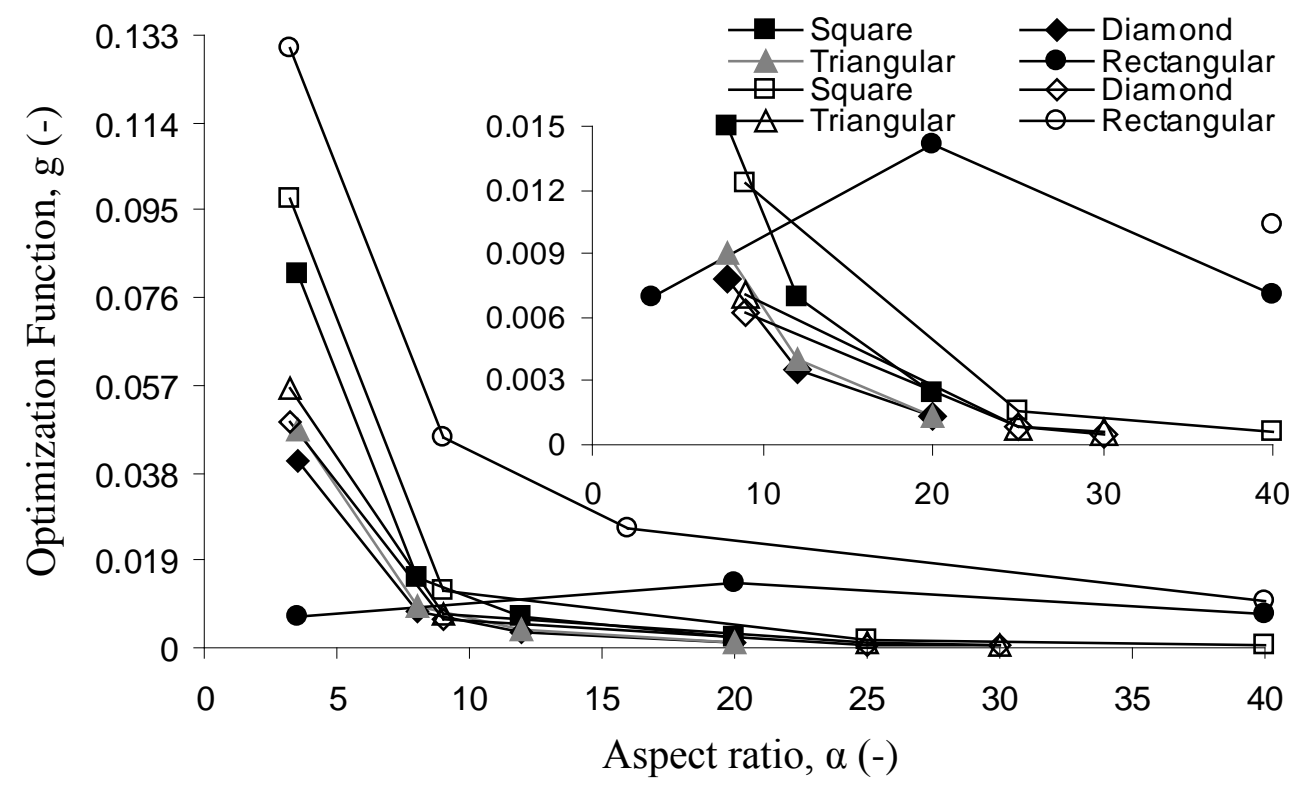

Figure 6. 


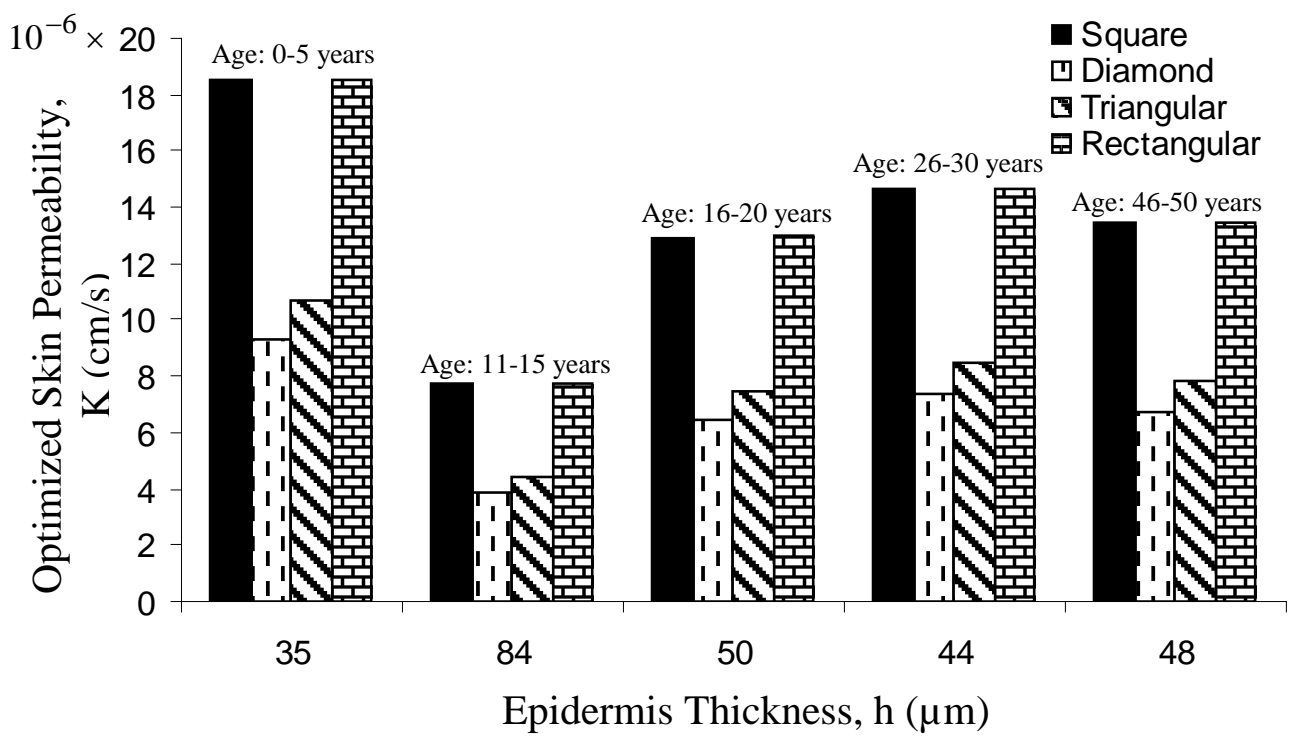

Figure 7. 


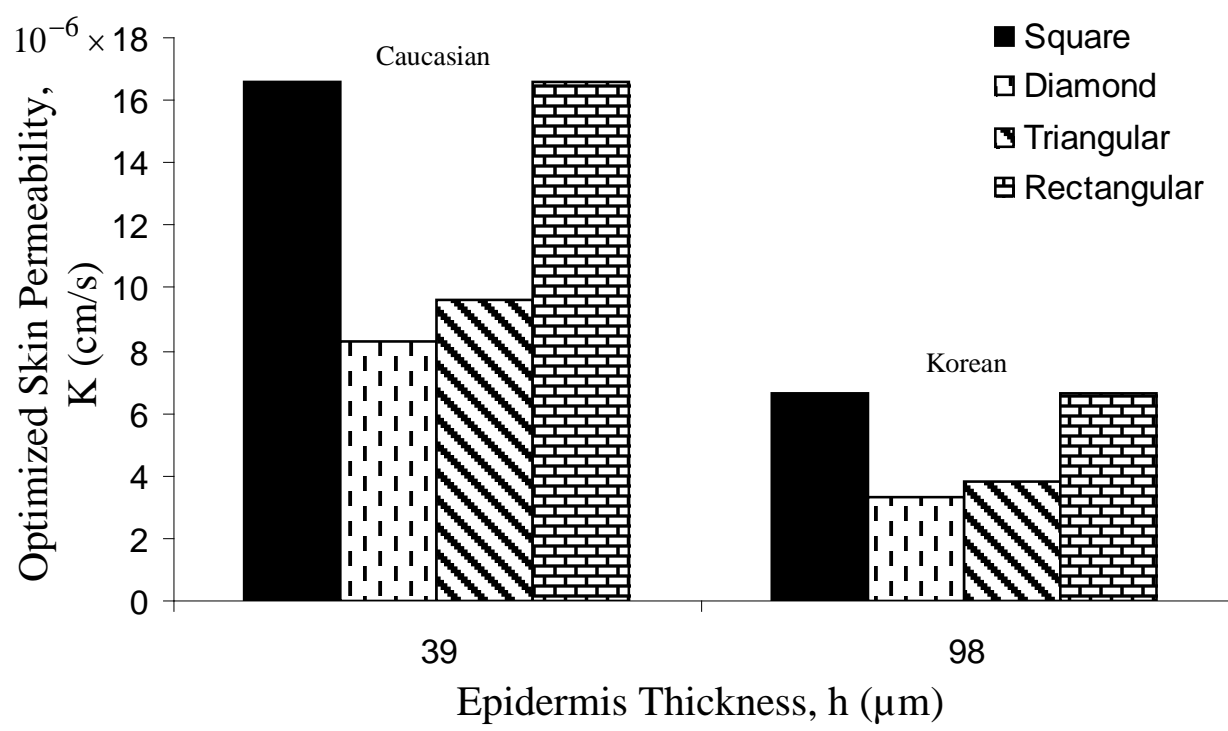

Figure 8. 


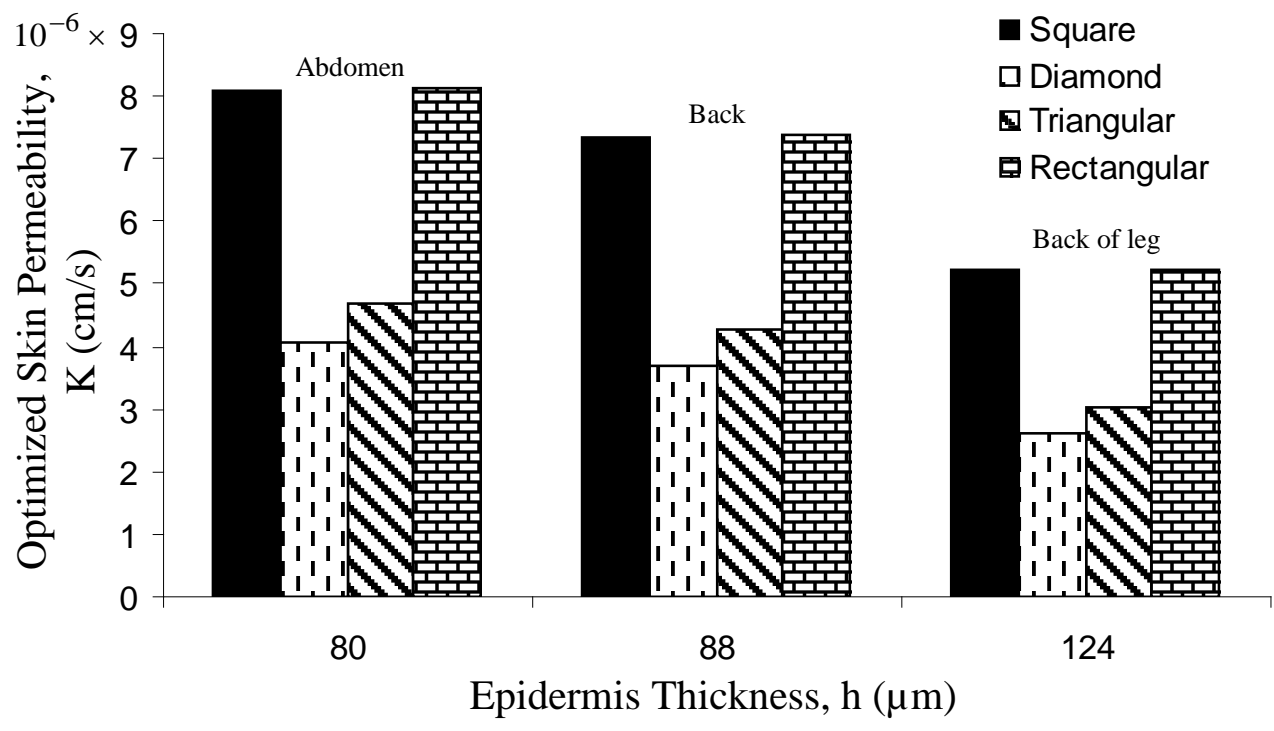

Figure 9. 


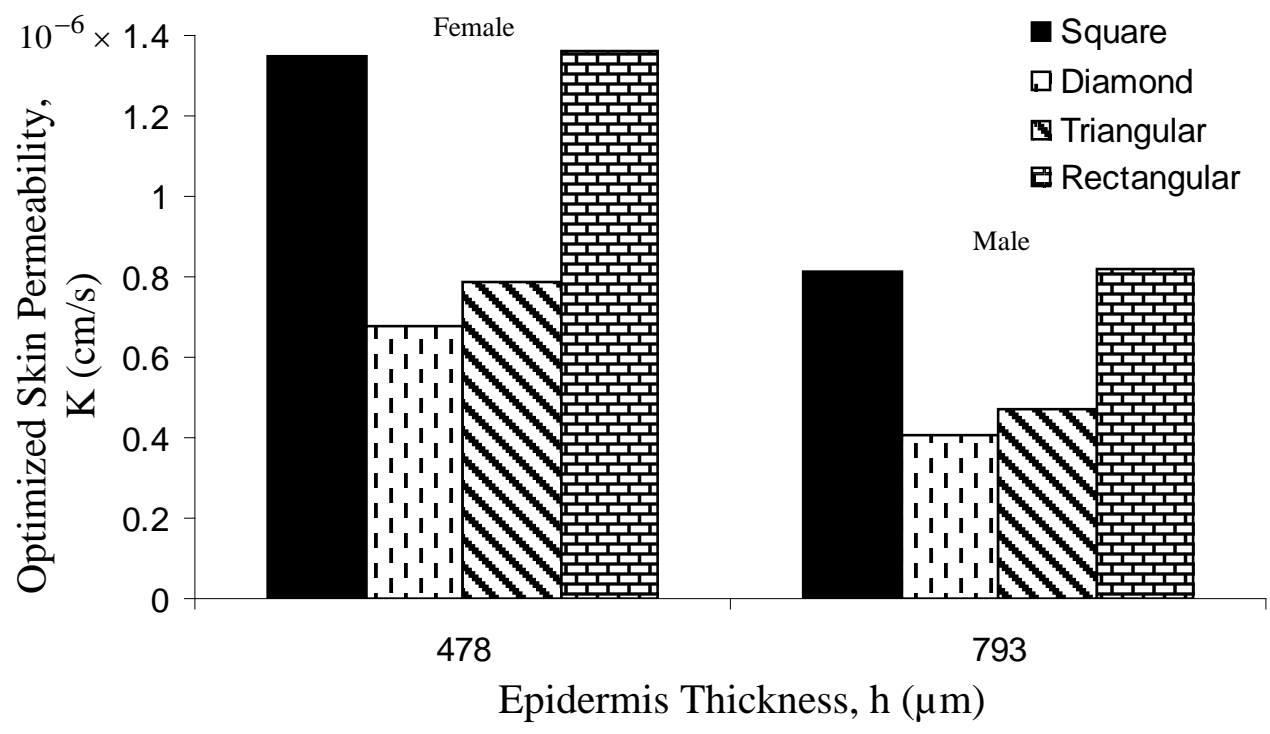

Figure 10. 


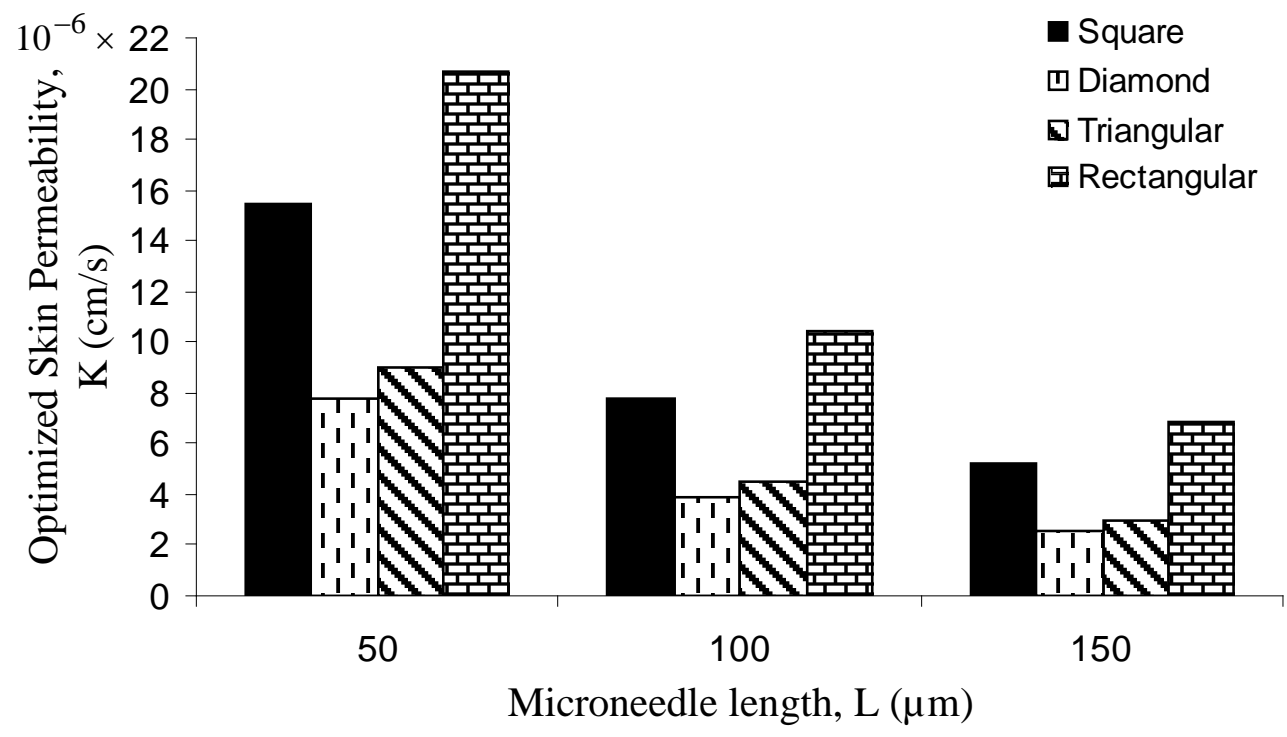

Figure 11. 


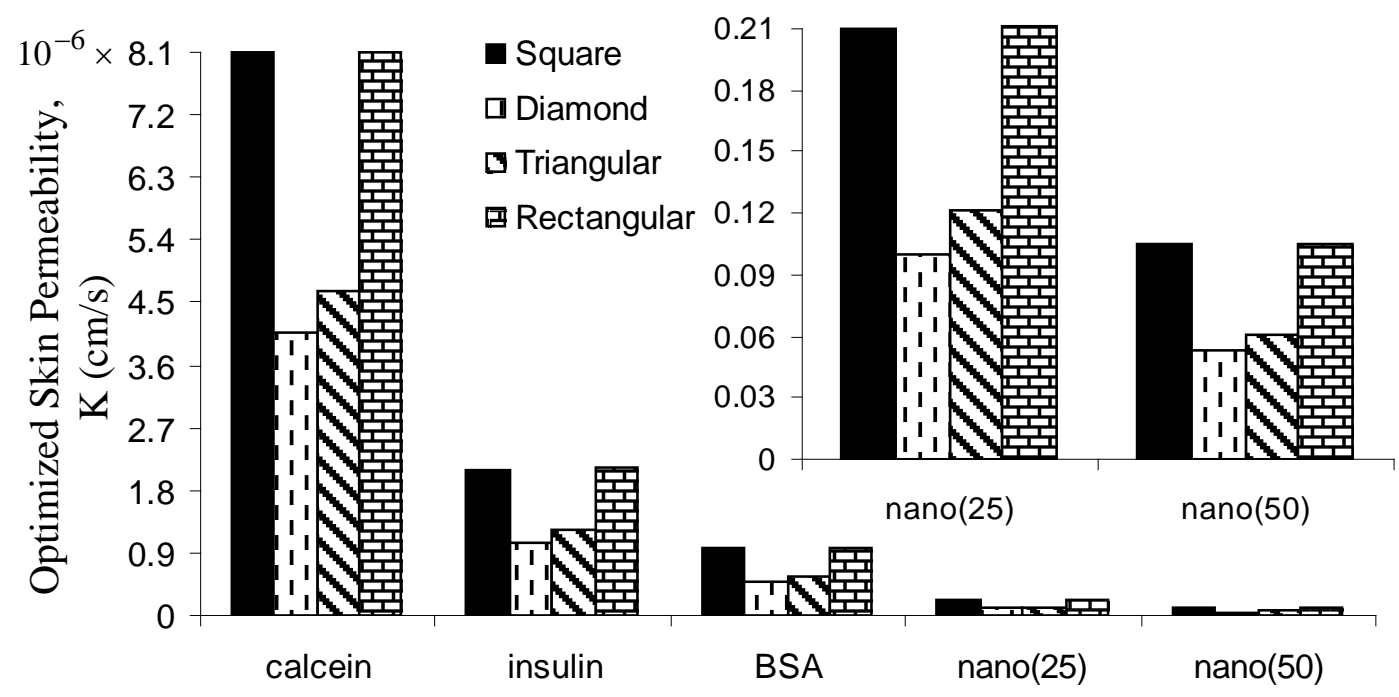

Figure 12. 


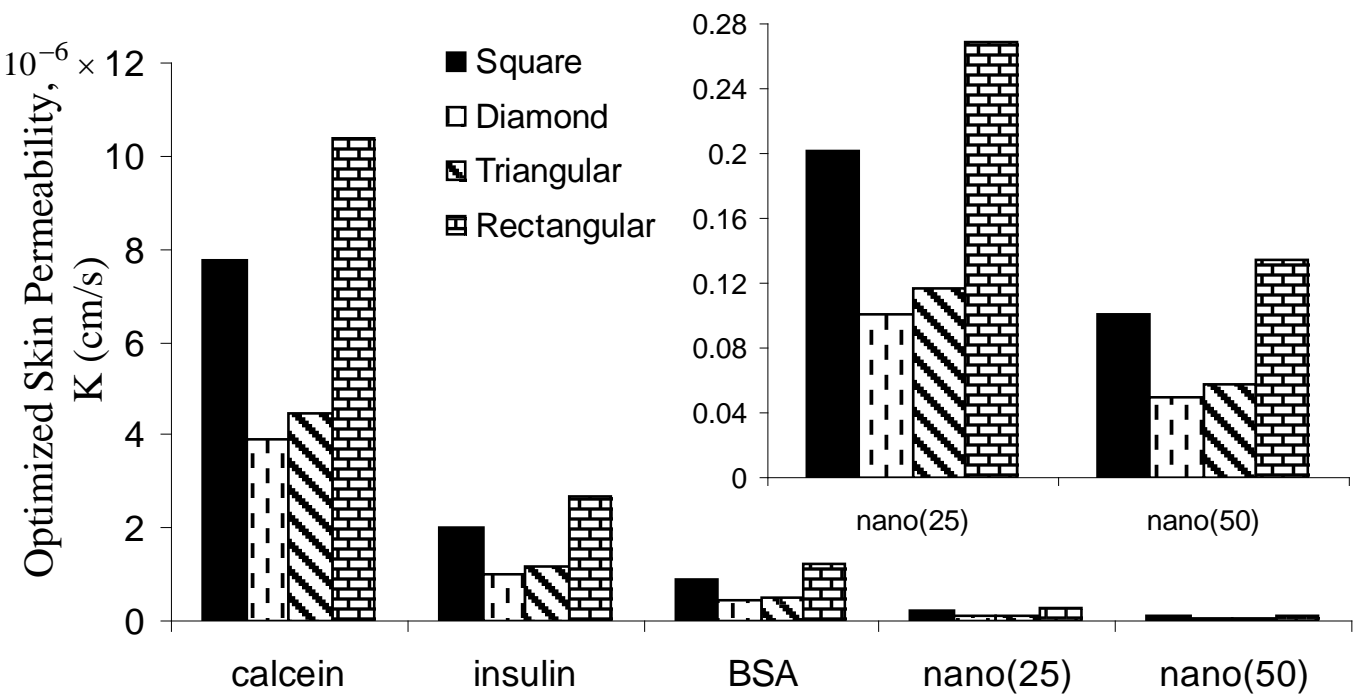

Figure 13. 


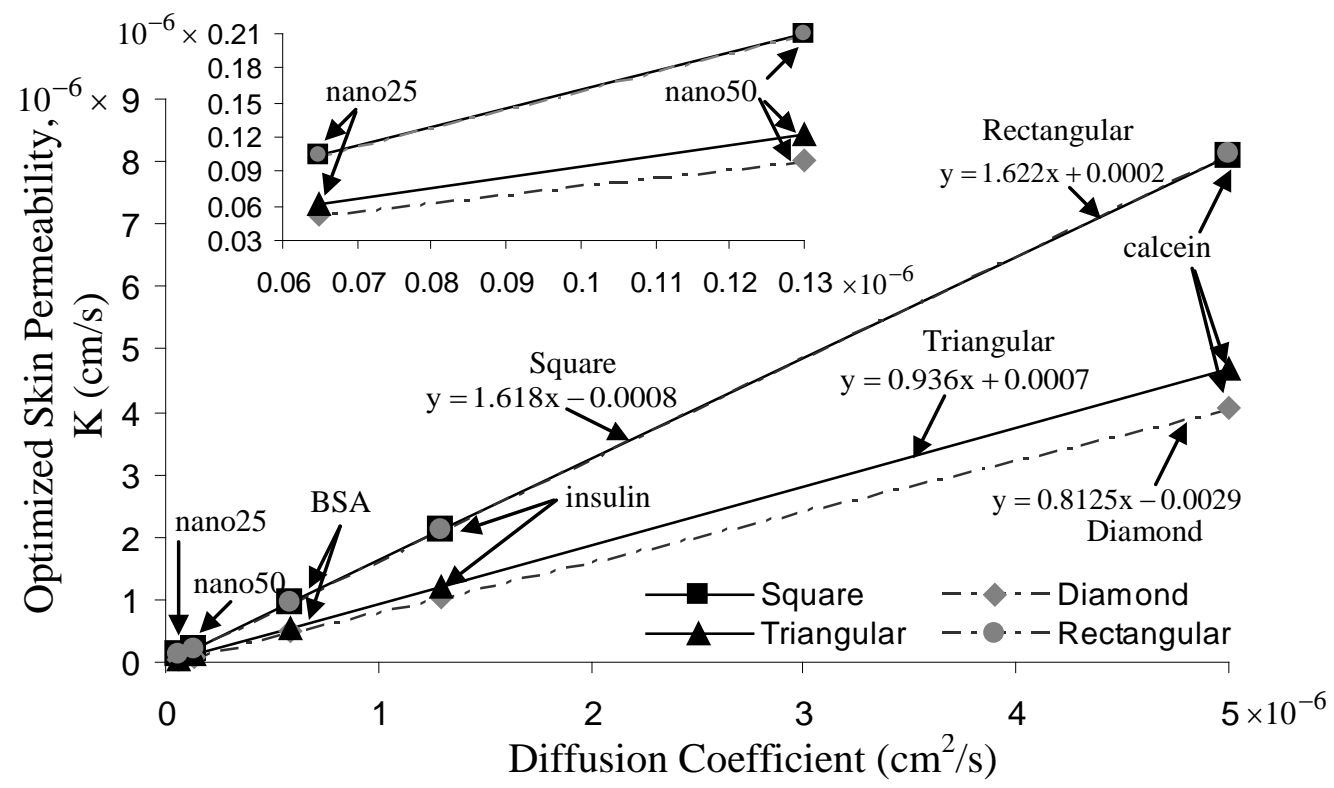

Figure 14. 


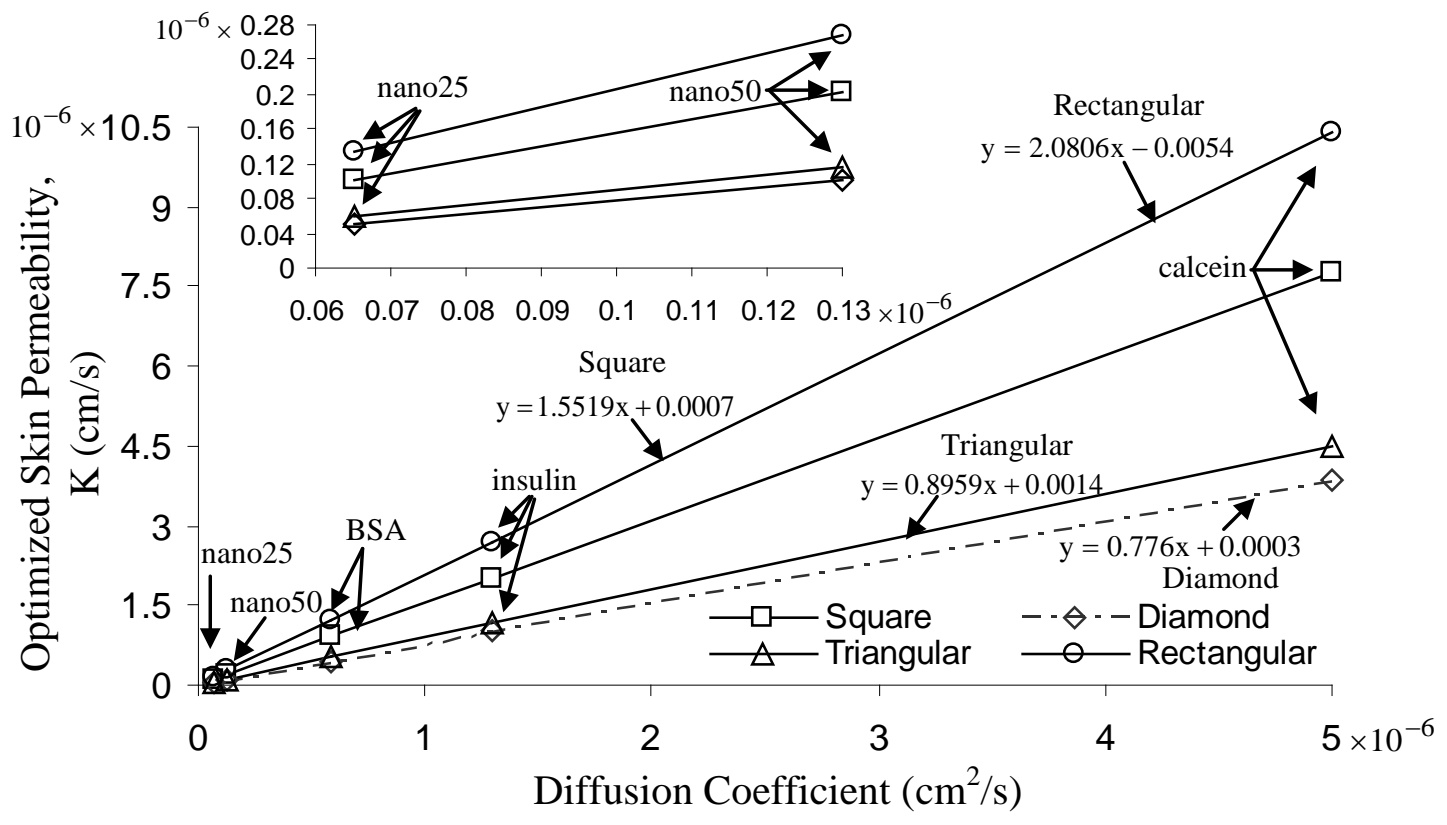

Figure 15. 